\title{
HYDROCARBON GEOSCIENCE
}

\section{RESEARCH STRATEGY}
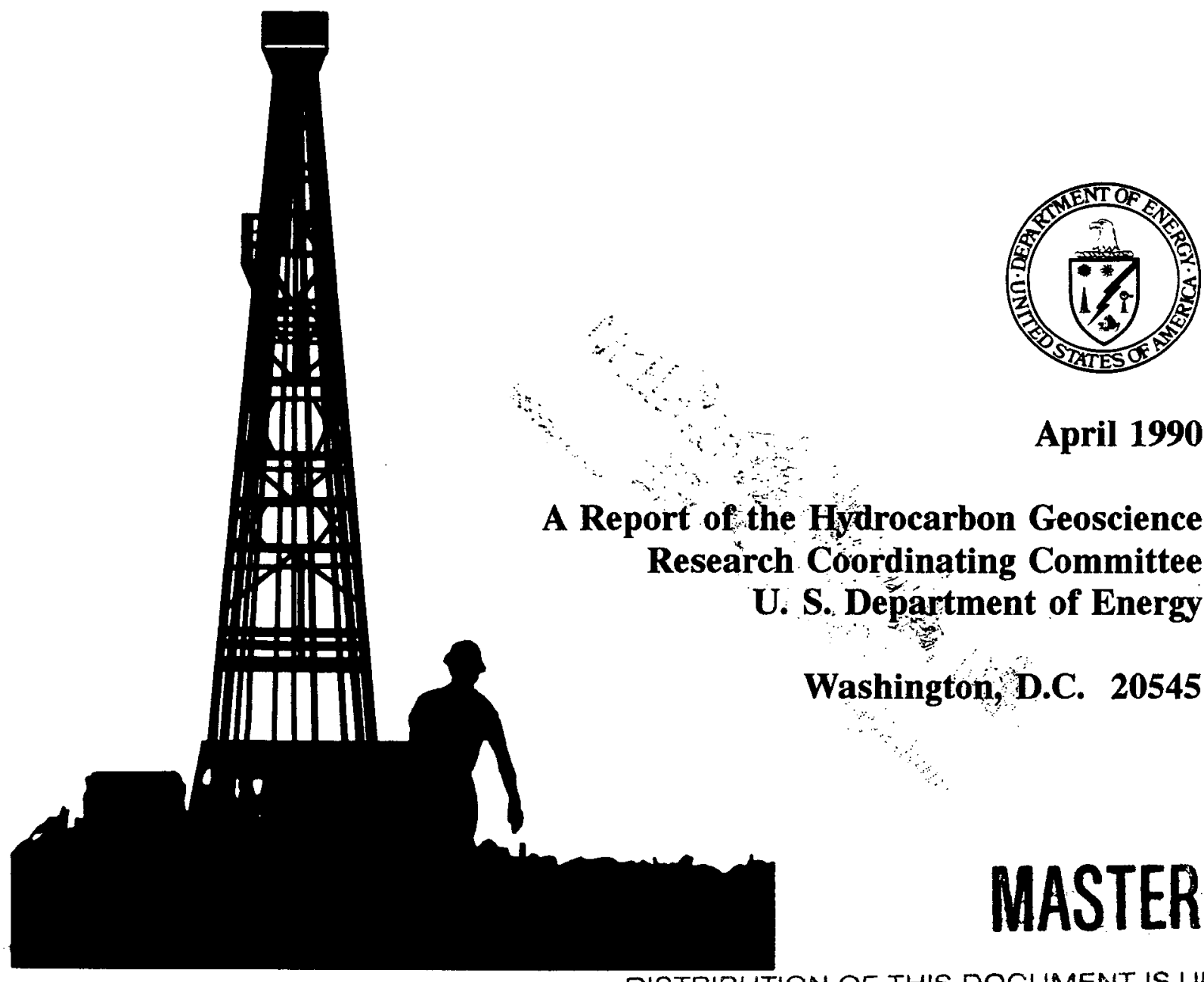

April 1990

A Report of the Hydrocarbon Geoscience rch Coordinating Committee U. S. Department of Energy Washington, D.C. 20545 


\section{DISCLAIMER}

This report was prepared as an account of work sponsored by an agency of the United States Government. Neither the United States Government nor any agency Thereof, nor any of their employees, makes any warranty, express or implied, or assumes any legal liability or responsibility for the accuracy, completeness, or usefulness of any information, apparatus, product, or process disclosed, or represents that its use would not infringe privately owned rights. Reference herein to any specific commercial product, process, or service by trade name, trademark, manufacturer, or otherwise does not necessarily constitute or imply its endorsement, recommendation, or favoring by the United States Government or any agency thereof. The views and opinions of authors expressed herein do not necessarily state or reflect those of the United States Government or any agency thereof. 


\section{DISCLAIMER}

Portions of this document may be illegible in electronic image products. Images are produced from the best available original document. 
$$
\text { . }
$$ 


\section{PREFACE}

This document outlines a strategy for oil and gas related research focused on optimizing the economic producibility of the Nation's resources. The Hydrocarbon Geoscience Strategy was developed by the Hydrocarbon Geoscience Research Coordinating Committee of the Department of Energy (DOE). This strategy forms the basis for the development of DOE Fossil Energy's Oil Research Program Implementation Plan and Natural Gas Program Implementation Plan.

Because the Hydrocarbon Geoscience Research Strategy was developed before the completion of the National Energy Strategy (NES), it may be subject to modification that aligns it with other NES initiatives. We expect that this strategy will become a key part of the Department's initiatives under the NES.

This strategy has been extensively reviewed. A draft was released to the public in December 1989 and was the subject of a public meeting in Washington, D.C. in January 1990. Follow-up comments from the public were useful in helping revise the draft. 


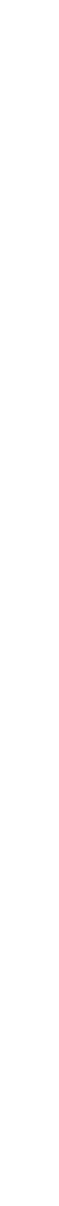




\section{TABLE OF CONTENTS}

$\underline{\text { Page }}$

EXECUTIVE SUMMARY $\ldots \ldots \ldots \ldots \ldots \ldots \ldots \ldots \ldots \ldots \ldots \ldots \ldots$ ix

CHAPTER 1 INTRODUCTION $\ldots \ldots \ldots \ldots \ldots \ldots \ldots \ldots \ldots \ldots \ldots \ldots$

BACKGROUND ......................... 1

DOE GEOSCIENCE PROGRAM OVERVIEW ................ 2

CHAPTER 2 THE NEED FOR HYDROCARBON GEOSCIENCE RESEARCH . . . . . 5

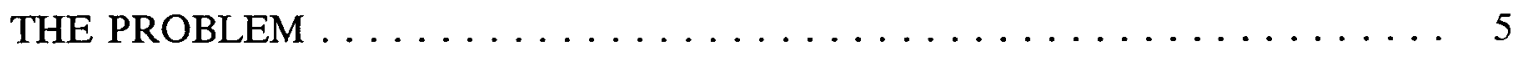

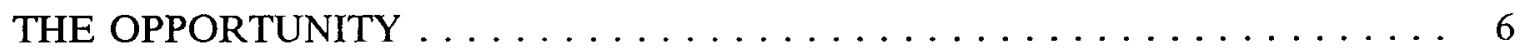

Oil and Natural Gas Liquids . . . . . . . . . . . . . . . . 6

Natural Gas .............................. 7

BARRIERS TO RECOVERY $\ldots \ldots \ldots \ldots \ldots \ldots \ldots \ldots \ldots$

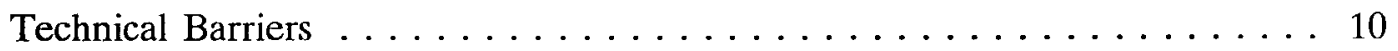

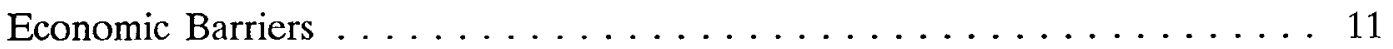

Institutional and Regulatory Barriers $\ldots \ldots \ldots \ldots \ldots \ldots \ldots \ldots$

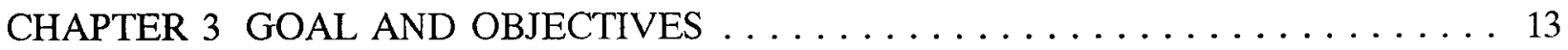

THE STRATEGIC GOAL $\ldots \ldots \ldots \ldots \ldots \ldots \ldots \ldots \ldots \ldots \ldots \ldots \ldots \ldots$

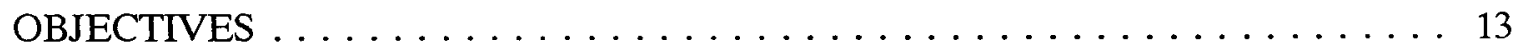

Near-Term Objective (Results produced in 5 years or less) . . . . . . . . 14

Mid-Term Objectives (Results produced in 10 years or less) . . . . . . . . 14

Long-Term Objectives (Results produced beyond 10 years) . . . . . . . . . . 14

CHAPTER 4 STRATEGY FOR IMPROVED OIL AND GAS DISCOVERY AND

RECOVERY ......................... 17

CONSIDERATIONS IN STRATEGY DEVELOPMENT . . . . . . . . . . . 17

Resource Focus $\ldots \ldots \ldots \ldots \ldots \ldots \ldots \ldots \ldots \ldots$ 
Integration Across Objectives $\ldots \ldots \ldots \ldots \ldots \ldots \ldots \ldots \ldots \ldots \ldots$

Technology Transfer . . . . . . . . . . . . . . . . 19

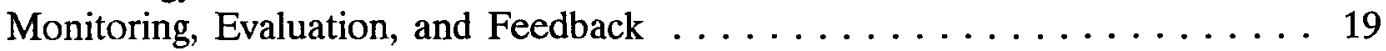

Economic Assumptions . . . . . . . . . . . . . . . . 19

STRATEGY FOR ACHIEVING THE NEAR-TERM OBJECTIVE $\ldots \ldots \ldots \ldots \ldots 20$

STRATEGY FOR ACHIEVING THE MID-TERM OBJECTIVES . . . . . . 24

STRATEGY FOR ACHIEVING THE LONG-TERM OBJECTIVES $\ldots \ldots \ldots 28$

BENEFITS AND RESERVES TARGETS $\ldots \ldots \ldots \ldots \ldots \ldots \ldots \ldots \ldots \ldots 31$

CHAPTER 5 TECHNOLOGY TRANSFER $\ldots \ldots \ldots \ldots \ldots \ldots \ldots \ldots \ldots \ldots$

CHAPTER 6 APPROACH TO IMPLEMENTATION $\ldots \ldots \ldots \ldots \ldots \ldots \ldots \ldots$

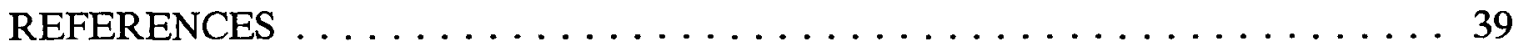

Appendix A CHARTER: DEPARTMENT OF ENERGY (DOE) HYDROCARBON GEOSCIENCE RESEARCH COORDINATING COMMITTEE (HGRCC)

Appendix B PROGRAM MISSION STATEMENTS $\ldots \ldots \ldots \ldots \ldots \ldots \ldots$ B-1 


\section{LIST OF FIGURES}

$\underline{\text { Page }}$

Figure 1 Over 300 Billion Barrels of Oil Remain in Known Reservoirs . . . . . . 7

Figure $2 \quad$ Unrecovered Mobile Oil and Immobile Oil $\ldots \ldots \ldots \ldots \ldots$

Figure $3 \quad$ Distribution of Natural Gas Resource $\ldots \ldots \ldots \ldots \ldots$

Figure $4 \quad$ Overview of DOE Geoscience Research Strategy . . . . . . . . . . 18

Figure 5 DOE Geoscience Research Strategy Targets - Significant Reserve Additions . . . . . . . . . . . . . . . . . . . . . . . . . . 34

\section{LIST OF TABLES}

Table $1 \quad$ Research Topics for Near-Term Objectives $\ldots \ldots \ldots \ldots \ldots$

Table $2 \quad$ Research Topics for Mid-Term Objectives . . . . . . . . . . . 29

Table $3 \quad$ Research Topics for Long-Term Objectives . . . . . . . . . . . 32 


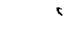

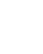

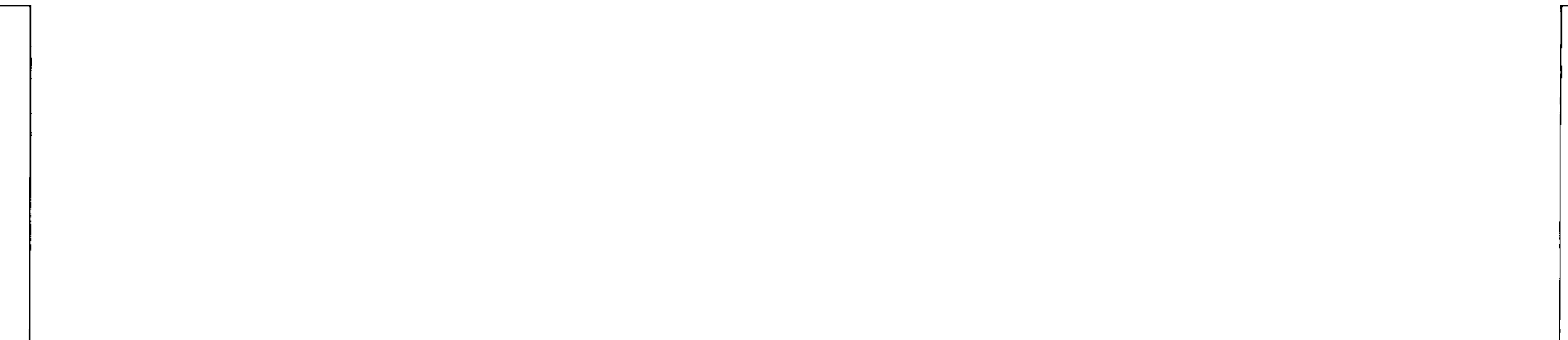




\section{EXECUTIVE SUMMARY}

Domestic oil and gas production is critical to maintaining our national energy and economic security. With this production in natural decline, the large national resource of currently unproducible oil and gas takes on special significance. Geoscience research, aimed at understanding the earth processes and technologies related to the discovery and recovery of hydrocarbon resources, can enhance producibility of the domestic resource. The Department of Energy (DOE) Hydrocarbon Geoscience Research Coordinating Committee (HGRCC) has responded to the need for a focused, integrated federal hydrocarbon geoscience research effort by developing this strategy.

Increased U.S. reliance on imported oil threatens national energy and economic security. Transportation, our largest user of oil, alone consumes more oil than is produced domestically. Recently, lower oil prices have curtailed production from higher-cost properties, accelerating the natural decline of mature domestic reservoirs. Marginal producing wells are being plugged and abandoned at an accelerating rate. Reserves of natural gas, an economical, environmentally acceptable alternative to oil, are also declining.

Technological, economic, and institutional constraints limit the amount of oil and gas that can be found and produced by conventional means. Two-thirds of all oil and over a third of the gas discovered will remain in known reservoirs after conventional production. As wells are abandoned, economic access to these resources becomes more limited, creating an urgency to act quickly to preserve the economic viability of these fields. Production of natural gas in unconventional geologic formations, representing an additional large resource, is similarly constrained by limitations in geoscience knowledge and technology. Finally, while the U.S. is a mature exploration region, substantial oil and gas remain to be discovered. Geoscience research can develop ways to find and recover more of these oil and gas resources, although actual conversion of resources to economically recoverable reserves depends not only on $R \& D$ and technology transfer success, but also on future economic, policy and regulatory conditions.

The strategic goal of the DOE hydrocarbon geoscience research program is to: increase significantly the economic producibility of domestic oil and gas resources through geoscience research and related activities. This goal focuses on oil and gas, for which geoscience research is considered most critical to improving the domestic energy situation.

The research objectives for achieving the strategic goal have been divided into three time frames reflecting the periods within which research products will be available: Near-term objectives will yield results in five years or less; mid-term objectives in up to ten years; and long-term objectives beyond ten years. Research aimed at all of these objectives will be conducted simultaneously, with results in one area benefiting ongoing research in other areas. Achievement of the mid- and long-term objectives depends on successful results in earlier stages. This strategy enhances the focus of hydrocarbon geoscience research within the Department. DOE's fiscal year 1991 budget request to Congress and future year budget projections reflect changes consistent with these objectives.

The objective of the near-term strategy is: to maintain economic access to the resources in currently producing domestic fields and decrease the rate of decline of domestic oil production by application of currently available technology. Efforts under this objective will start with a detailed analysis to determine which classes of reservoir both have significant future potential and are at risk of imminent abandonment. The most urgent of these will be addressed in ways that sustain production, e.g., application of 
currently available reservoir characterization techniques and production strategies. For reservoirs that cannot be sustained through such methods, techniques will be developed for environmentally sound alternatives to plugging of wells with cement to maintain future access when newer technologies become available.

The mid-term objectives are focused in three areas: maximizing the recovery of oil and gas through improved understanding of the resource and the development of advanced extraction techniques; increasing the efficiency of resource discovery; and expanding environmental understanding to keep pace with advances in extraction technology. Reservoirs will be classified according to their geological histories and properties. Reservoir classes with the greatest potential will be given high priority for focused, interdisciplinary research to increase economic producibility. This research will define the principal features of reservoir architecture and flow paths, and will design and test techniques for producing additional oil and gas from conventional and unconventional resources, known and undiscovered. Supporting these efforts will be advancements in measurement and interpretation of reservoir properties and mathematical techniques to simulate the operations of recovery processes in complex reservoirs. Environmental research will be conducted to evaluate and mitigate the environmental impacts of these advanced technologies.

The long-term strategy has two broad objectives: improve the fundamental understanding of the oil and gas resource and support the community of scientists and researchers in the field of oil and gas discovery and recovery. The principal targets of long-term research are those oil and gas resources that cannot be made economically producible by the technologies being developed under the mid-term strategy. To address these targets, the research will focus on the fundamental physical, chemical, and biological phenomena that govern the occurrence and recovery of oil and gas. The research will be of two types. Sustaining basic research will emphasize creativity and scientific excellence in the context of the various geoscience disciplines. Supporting, mission-oriented basic research will address research problems identified through the short-term efforts by seeking revolutionary solutions in such areas as determining rock and fluid properties and overcoming physical constraints to production. Support of the research community is crucial to achieving the goal by ensuring sufficient scientific and technical personnel to develop and apply the new technologies.

Integration of effort is necessary to achieve this goal. A common base of data, assumptions, and theory will guide the selection of research priorities in each time interval. Interaction will allow results developed in one area to be incorporated into ongoing projects in other areas.

A key to achieving oil and gas reserve additions is technology transfer. This is addressed two ways. First, the strategy uses specific operator problems in specific reservoirs as a basis for the design of research activities. Second, the program will use both established and innovative methods for delivering its products quickly and effectively to those who will implement them in the field.

Finally, the strategy includes the monitoring and evaluation of research results and feedback into the design of the research program. The strategy and implementation plans will be updated accordingly. 


\section{Chapter 1 \\ INTRODUCTION}

\section{BACKGROUND}

For the foreseeable future, the nation's energy needs will be met primarily by resources drawn from the earth. The Department of Energy (DOE) has long recognized the importance of understanding the structure of the earth and the physical and chemical nature of its energy resources. This understanding contributes to more efficient and economical recovery of those resources, which in turn improves the economic health, national security and environmental well-being of the country.

Several groups have issued reports recently discussing the energy situation and the need for various kinds of research in the solid earth sciences and related disciplines. Probably the most prominent and comprehensive of these reports is Geoscience Research for Energy Security, which was prepared by DOE's Energy Research Advisory Board (ERAB) in February 1987 (DOE, 1987b). In this report, ERAB discussed the critical role that geoscience research must play in solving the nation's energy problems and placed priorities on that research. The highest priority was placed on oil and gas research. ERAB stated, "The major energy problem facing the United States is a shortage of domestic liquid hydrocarbons, which threatens the nation's long-term energy security and international competitiveness." Among its several recommendations were better coordination of the geoscience research programs within DOE and with other government agencies, and the development of strategic plans "to ensure that the geoscience research needs of the energy industry and DOE programs are identified and appropriately supported."
DOE has responded to these recommendations by establishing the Hydrocarbon Geoscience Research Coordinating Committee (HGRCC), with representation from all DOE programs and other federal agencies that conduct hydrocarbon geoscience research, including the U.S. Geological Survey (USGS), the Minerals Management Service (MMS), and the National Science Foundation (NSF). The HGRCC, as part of its charter, has responsibility for developing an integrated strategic plan for hydrocarbon geoscience research activities within the Department. In addition, an Office of Geoscience Research (OGR) was created under the Assistant Secretary for Fossil Energy to serve as the focus of hydrocarbon geoscience research policy and strategy in the Office of Fossil Energy and as an advocate and coordinator of hydrocarbon geoscience research programs in DOE. The charter of the HGRCC and the mission statement of the OGR are contained in Appendix A.

Others also have responded to the need for coordinated research in this area. Universities, state geological surveys and laboratories have formed consortia to conduct hydrocarbon geoscience research (e.g., Geoscience Institute, 1989). Congress has emphasized the importance of DOE hydrocarbon geoscience research and urged the Department to develop a research strategy (USHR, 1988-89). This document has been prepared in response to these recommendations and requests, as partial fulfillment of the HGRCC charter, and in recognition of the importance of having an integrated strategy to provide direction for DOE hydrocarbon geoscience research activities. 


\section{DOE GEOSCIENCE PROGRAM OVERVIEW}

The major DOE research programs have specific and well-defined missions, many of which have a geoscience component. A perspective on the breadth of geoscience activities within DOE may be helpful in evaluating the more specific issues that are the focus of this document. Briefly, DOE geoscience related activities are:

- The Office of Fossil Energy conducts fundamental and applied research on the development of technologies to characterize and extract hydrocarbon resources. This research is carried out with four programs: Advanced Extraction and Process Technology, Enhanced Oil Recovery, Unconventional Gas Recovery, and Oil Shale. Geoscience activities are also part of the operations of the Naval Petroleum and Oil Shale Reserves and the Strategic Petroleum Reserves within this office.

- The Office of Energy Research conducts basic, discipline-oriented research aimed at understanding earth structure and processes. Geoscience research is contained primarily within two programs: Basic Energy Sciences and Health and Environmental Research.

- The Office of Conservation and Renewable Energy develops technology needed to exploit the country's geothermal resources through applied $R \& D$.

- The Office of Civilian Radioactive Waste Management characterizes sites and will construct and operate facilities for the storage and geologic disposal of spent nuclear fuel high-level radioactive waste from commercial and atomic energy defense activities.

- The Office of Nuclear Energy supports a small amount of geoscience research in connection with its seismic technology development program. That research has its application in advance of nuclear powerplant design and construction activities.

- The Office of Defense Programs develops the nation's nuclear weapons and is concerned with the geoscientific aspects of safely emplacing and executing underground nuclear explosive tests, of measuring yields of these tests by seismic means, and of safely disposing of wastes produced by its programs.

Geoscience research activities are conducted through these programs either as an integral part of an $R \& D$ program or in support of other specific objectives (e.g., site-specific studies to optimize oil production or construct a storage cavern). Mission statements for these programs are contained in Appendix B.

Several agencies outside DOE also conduct geoscience research. The USGS and the MMS within the Department of the Interior and the NSF have specific statutory missions with large geoscience components. Their mission statements are also contained in Appendix B. Other agencies with geoscientific research components in their programs include the National Oceanographic and Atmospheric Administration within the Department of Commerce, the Bureau of Mines and Bureau of Land Management in the Department of the Interior, and the National Aeronautics and Space Administration.

The charter of the HGRCC relates to only a specific segment of these program areas, Hydrocarbon Geoscience Research, which covers oil, gas, coal, tar sands, and oil shale. This research is spread across several DOE programs' and touches on other agencies as well. Also, it is recognized that some 
programs not specifically concerned with hydrocarbons may contain research applicable to the search for and recovery of hydrocarbons.

The HGRCC charter contains a definition of its area of concern:

\section{Hydrocarbon Geoscience Research includes research and development activities directed towards the discovery and recovery of hydrocarbon resources especially in oil and gas.}

This is a broad statement, and is meant to define the area of concern for purposes of this strategy. It is not a scientific definition of a technical term. Further, because it is mission-oriented, it encompasses not only the geological science of the formation, maturation, migration, and accumulation of hydrocarbons, but also the disciplines and technologies related to discovery and recovery (e.g., petroleum engineering). This definition includes both activities specifically directed toward hydrocarbon discovery and recovery and those not primarily undertaken to find and produce hydrocarbons but with clear potential for application in this area, e.g., drilling research aimed at other targets. It does not, however, include the refining, conversion, or transportation activities that occur after recovery.

The emphasis in this document is on oil and gas. Domestic oil and gas production have been identified by ERAB and others (DOE, 1987a; NPC, 1987) as the critical energy supply issue affecting the country's energy security and economic health. This does not mean that other hydrocarbons are not being addressed by the research programs; it simply means that this first effort is focused on the areas identified by ERAB and others as having the highest priority. Other hydrocarbons will be addressed in the future, when the strategy is revised to reflect program progress.

This strategy is not a program implementation plan. It does not describe specific research projects or present programmatic milestones. It is intended as guidance to the program offices that conduct the research to assist them in developing their program implementation plans and budget requests. Through the HGRCC and its members who have participated in developing this strategy, the guidance contained here will receive maximum consideration by all offices working in the area. 


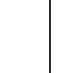

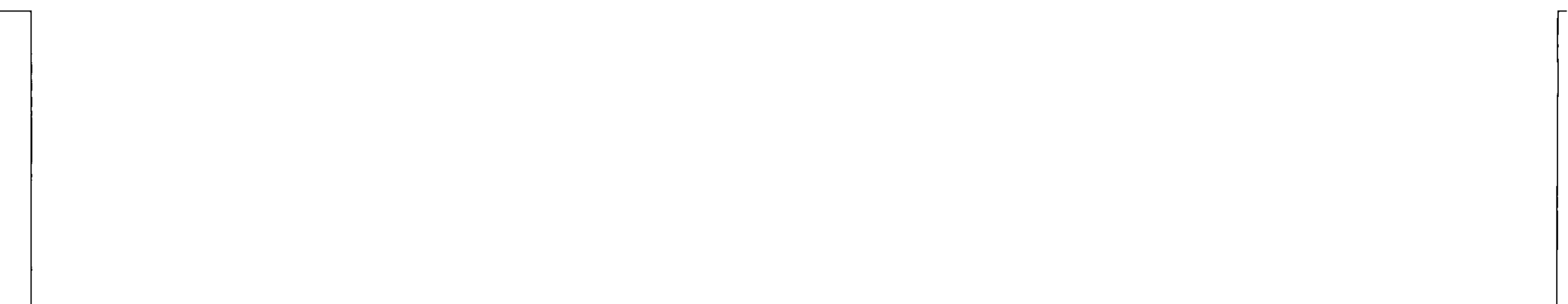




\section{Chapter 2 \\ THE NEED FOR HYDROCARBON \\ GEOSCIENCE RESEARCH}

\section{THE PROBLEM}

The U.S. economy is the largest in the world and its health depends on plentiful supplies of energy. Oil and gas play a major role in fueling the growth of this immense economy. The transportation sector alone demands almost two-thirds of the petroleum used in this country, about $17 \%$ more than was produced domestically in 1989 . Petroleum provided $97.1 \%$ of transportation fuel needs. No broadly applicable substitute currently exists in this sector, other than natural gas which provided $2.7 \%$ of transportation consumption in 1989 (EIA, 1990b).

The threat of abrupt oil supply curtailments and price increases lies at the heart of U.S. energy security. But, even in the absence of an oil price "shock," the national reliance on imports negatively affects economic growth. The annual level of imports is projected to rise from $\$ 46.5$ billion in 1989 to as much as $\$ 101$ billion in the year 2000 (EIA, 1990a). The U.S. imported $41.3 \%$ of its oil supply in 1989 to meet its excess domestic demand (EIA, 1990b). Most projections show U.S. oil imports exceeding $50 \%$ of domestic consumption by the early to mid-1990s (EIA, 1990a).

Domestic crude oil production has declined $16 \%$ since its peak in 1970 . In the contiguous states, production has fallen by $36 \%$ since 1970 and reserves have dropped by $31.1 \%$ (OGJ, 1989; EIA, 1989c). Alaska's Prudhoe Bay, a huge discovery of rare proportions, offset the Lower-48 decline from 1978 to 1985 , but it is beginning a natural production decline. Discovery of another field large enough to offset this decline is unlikely. Even if the Arctic National Wildlife Refuge were explored and developed, it would provide the equivalent of only about one year's worth of domestic production, assuming the mean estimate of recoverable resources were realized (DOI, 1987).

Even though the U.S. continues to drill more than half of the world's new wells, the reserve additions from new discoveries have been small (World Oil, 1988; EIA, 1989b). In 1981, the USGS mean estimate of recoverable undiscovered oil resources indicated that 82.6 billion barrels $(\mathrm{BBbl})$ remained to be discovered in the United States (including Alaska and offshore), but those estimates were reduced to $49.4 \mathrm{Bbbl}$ in 1988 (USGS, 1981; USGS-MMS, 1989). The Lower-48 portion of this amount was reduced by almost $60 \%$. While discoveries during the intervening eight years moved as much as $18 \mathrm{BBbl}$ from undiscovered into the discovered category, worsening economics and disappointing exploration experience in key basins account for the rest of the decrease.

Exploration and development activities peaked during the high oil price years of 1979 to 1984 and, because of lower prices, collapsed thereafter. In 1981, the number of domestic new-well completions peaked at about 90,000 , and by 1988 had decreased to about one-third as much (OGJ, 1989). For the U.S., a relatively mature oil and gas producing region, decline in reserves and production is predictable. Much of the drilling activity has moved overseas. Foreign oil is simply cheaper and more profitable to produce than domestic oil. 
In 1987, $73 \%$ of all producing oil wells in the U.S: were "stripper wells," i.e., those producing less than 10 barrels per day (bpd). These stripper wells produced an average of 2.7 bpd. They account for $15 \%$ of all domestic production and $20 \%$ of Lower-48 production (API, 1990; IOCC, 1989).

Furthermore, these wells are being abandoned at a rapid rate (DOE, 1989a). Abandonment regulations require that existing wells be plugged for environmental reasons. This limits future economic access to the resource remaining in these reservoirs at currently projected prices because of the high cost of reentering plugged wells or drilling new ones. Since 1980, the annual abandonment of stripper wells has increased $163 \%$, with 17,423 wells abandoned in 1988 (IOCC, 1989). Wells associated with as much as $40 \%$ of the remaining, but currently uneconomic, domestic oil resource may have already been plugged and abandoned, and the rate of abandonment has been increasing recently (DOE, 1989a).
Natural gas can substitute for oil in many applications and can thus serve to help reduce oil imports. However, gas reserves have also declined. While gas supplies are currently plentiful, this is expected to be a short-term phenomenon as demand rises for economic, environmental and technological reasons (EIA, 1989d). Largely due to air pollution concerns in major U.S. urban areas, and to technological advances, natural gas is becoming more attractive as a transportation fuel for urban fleets. Environmental concerns, together with seasonal economic considerations, may also significantly increase the gas share of electricity production and industrial energy demand. As demand for gas increases, and domestic supply in certain regions proves inadequate, particularly in northern areas of the country, natural gas imports are expected to continue growing. The Energy Information Administration (1990a) projects net gas imports to rise from 1.43 trillion cubic feet ( $\mathrm{Tcf}$ ) per year in 1989 to $2.68 \mathrm{Tcf}$ in 2000 .

\section{THE OPPORTUNITY}

Through 1987, the United States had produced $145 \mathrm{BBbl}$ of oil (API/AGA/CPA, 1980, DOE, 1989b) and 698 Tcf of natural gas (USGS-MMS, 1988) -- more than any other country in the world. Remaining economically recoverable proved reserves are about $27 \mathrm{BBbl}$ of crude oil, $8 \mathrm{BBbl}$ of natural gas liquids, and $168 \mathrm{Tcf}$ of natural gas (EIA, 1989b). If produced at current rates, these reserves would amount to about 9 and 10 years supply of oil and gas, respectively. Fortunately, large amounts of oil and gas remain in U.S. reservoirs, both discovered and undiscovered. The proportion of these resources that can be converted to economically recoverable reserves and, ultimately, production depends heavily on advances in the geosciences of discovery and recovery and on future economic conditions.
The opportunity can be measured by the magnitude of the resources.

\section{Oil and Natural Gas Liquids}

About $513 \mathrm{BBbl}$ of oil have been discovered to date, of which two-thirds, or 341 $\mathrm{BBbl}$ will remain in known fields at the conclusion of conventional recovery (DOE, $1989 \mathrm{~b}$ ). This remaining oil is of two types (Figure 1), and is distributed throughout the U.S. (Figure 2):

- Unrecovered Mobile Oil is displaceable by (mobile to) water or steam. Nearly 100 $\mathrm{BBbl}$ of this oil remains in place in U.S. reservoirs (DOE, 1989b), a portion of which could be produced through infill 


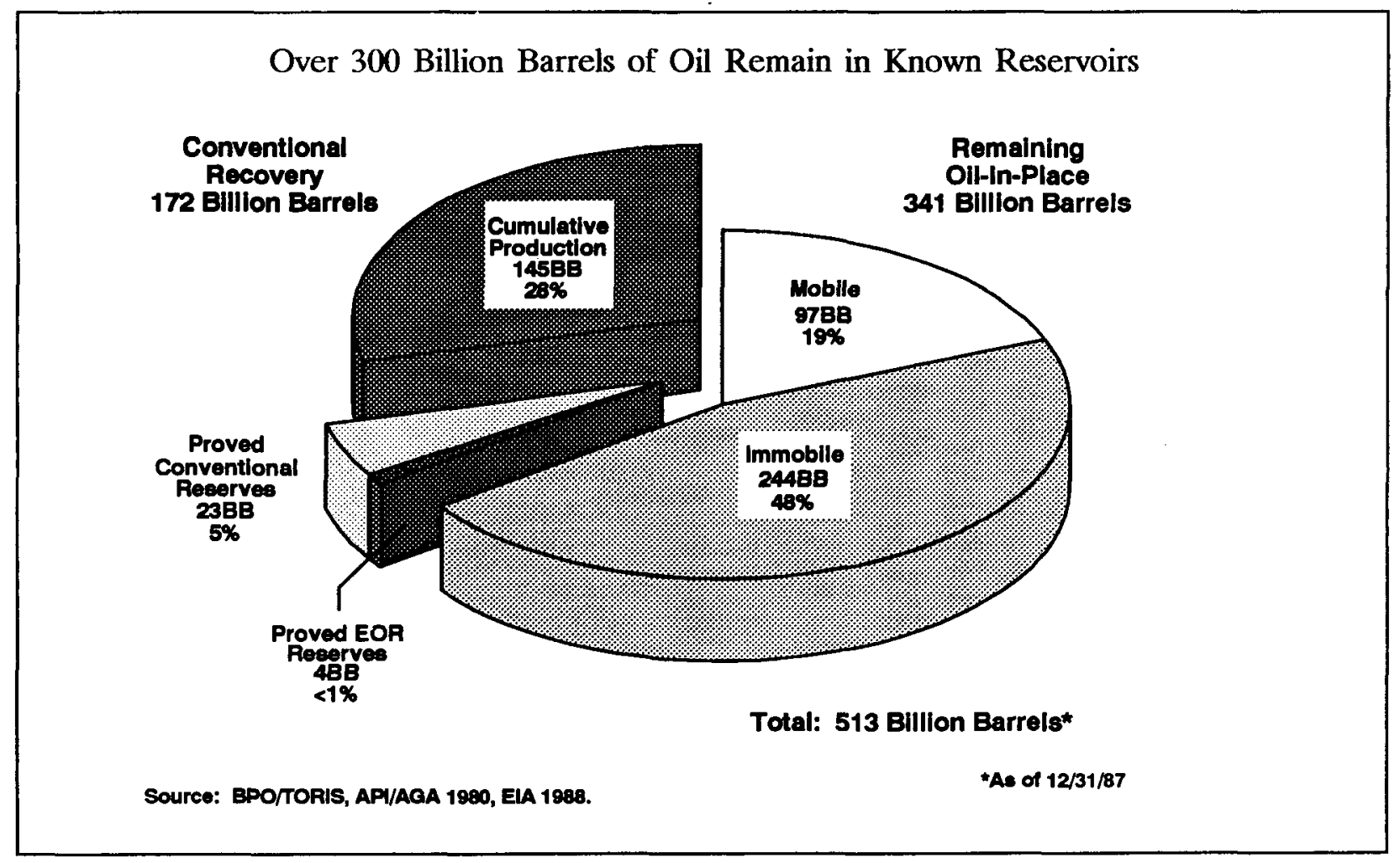

drilling and advanced secondary recovery methods.

- Immobile Oil is not displaceable by further injection of water and is therefore residual to secondary recovery methods. More than $240 \mathrm{BBbl}$ of immobile oil remain in place in known U.S. reservoirs (DOE, 1989b). Part of this oil could be produced through tertiary recovery methods.

In addition to these known resources, significant quantities of oil are believed to be undiscovered in new fields. The USGS and MMS have estimated that $49.4 \mathrm{BBbl}$ of recoverable oiland $8.6 \mathrm{BBbl}$ of recoverable natural gas liquids remain to be discovered in the U.S. (USGS-MMS, 1988). Finding these recoverable reserves would also add to the magnitude of the mobile and immobile resource targets.

\section{Natural Gas}

Recoverable U.S, natural gas resources are significant and consist of several components: reserves additions in known fields, resources in unconventional geologic settings, and undiscovered resources (Figure 3). A recent DOE assessment estimated that almost 1,200 Tcf of gas of all three types are technically recoverable (DOE, 1988a). In known fields, about 110 Tcf in reserves are expected to be added through the routine processes of field development (known as inferred reserves). An additional $180 \mathrm{Tcf}$ could be added through improved reservoir understanding and intensive infill drilling. "Unconventional natural gas" includes gas from low-permeability sandstone reservoirs (tight gas), coalbed methane, and gas from Devonian shale. An estimated 260 to $430 \mathrm{Tcf}$ are technically recoverable from these resources (DOE, 1988a). 
Figure 2

Unrecovered Mobile Oil

(Billions of Barreks)

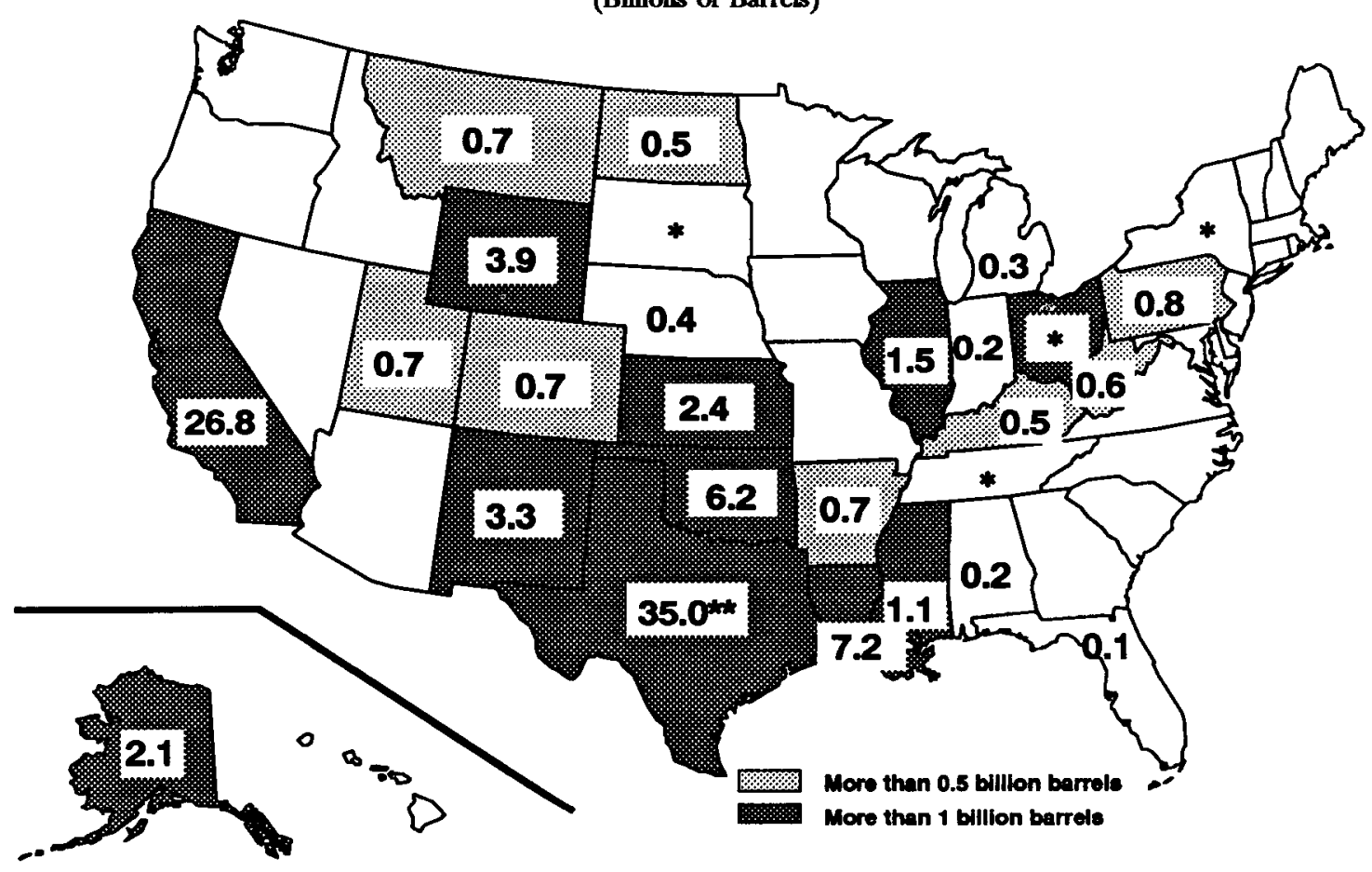

Immobile Oil

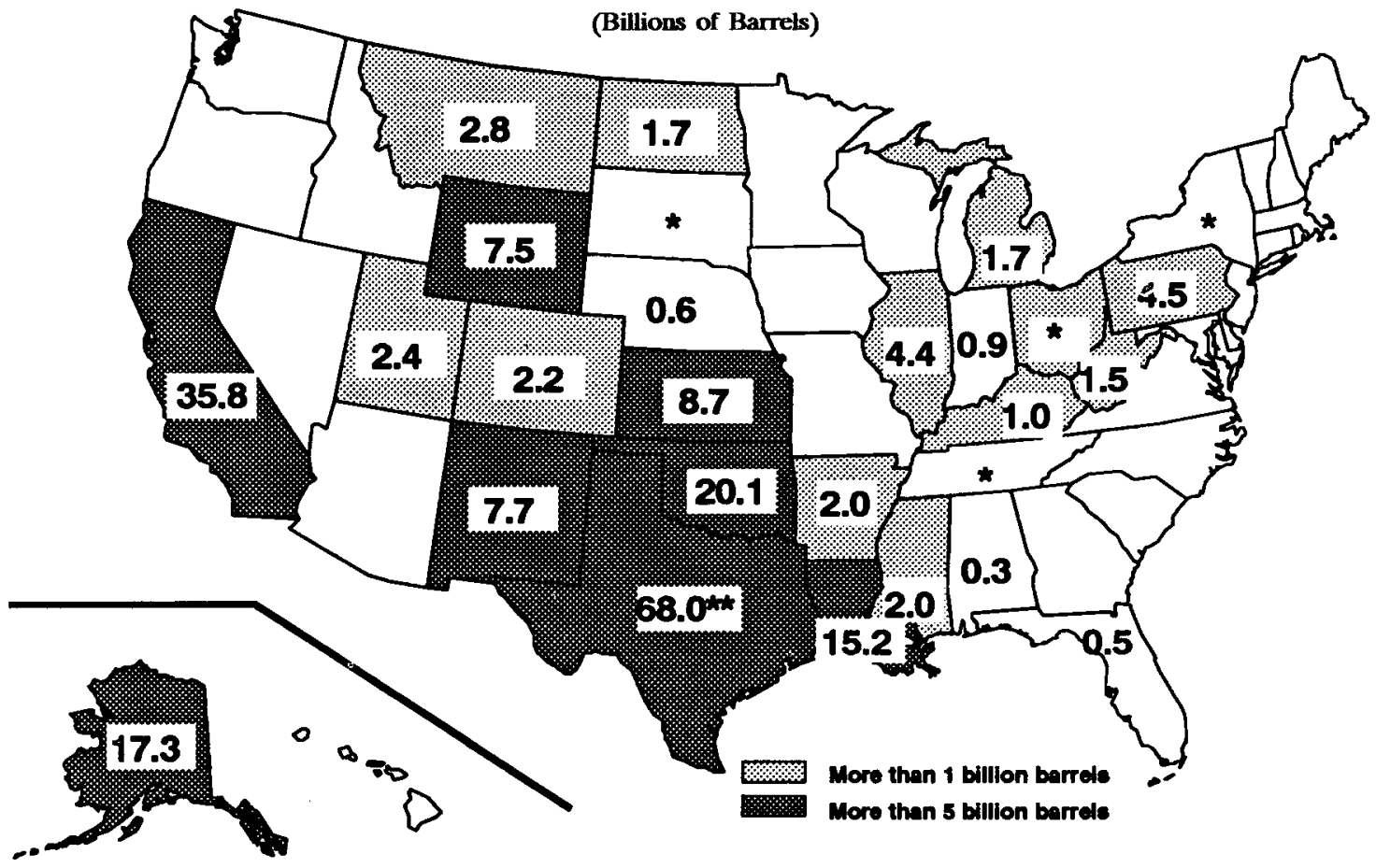

- Not enough Information to evaluate (except Ohio, where 6.3 billion berrels are known to remaln but deta are inauficient for cotimating mobile $v$. Immobile).

* Based on W.L. Fisher, Toxne Bureau of Economic Coology, 1887.

As of January 1, 1980. Calculations wing TOAIS based on API 1980 resource. 
Figure 3

\section{Distribution of Natural Gas Resources \\ Technically Recoverable Gas 1,188 TCF}

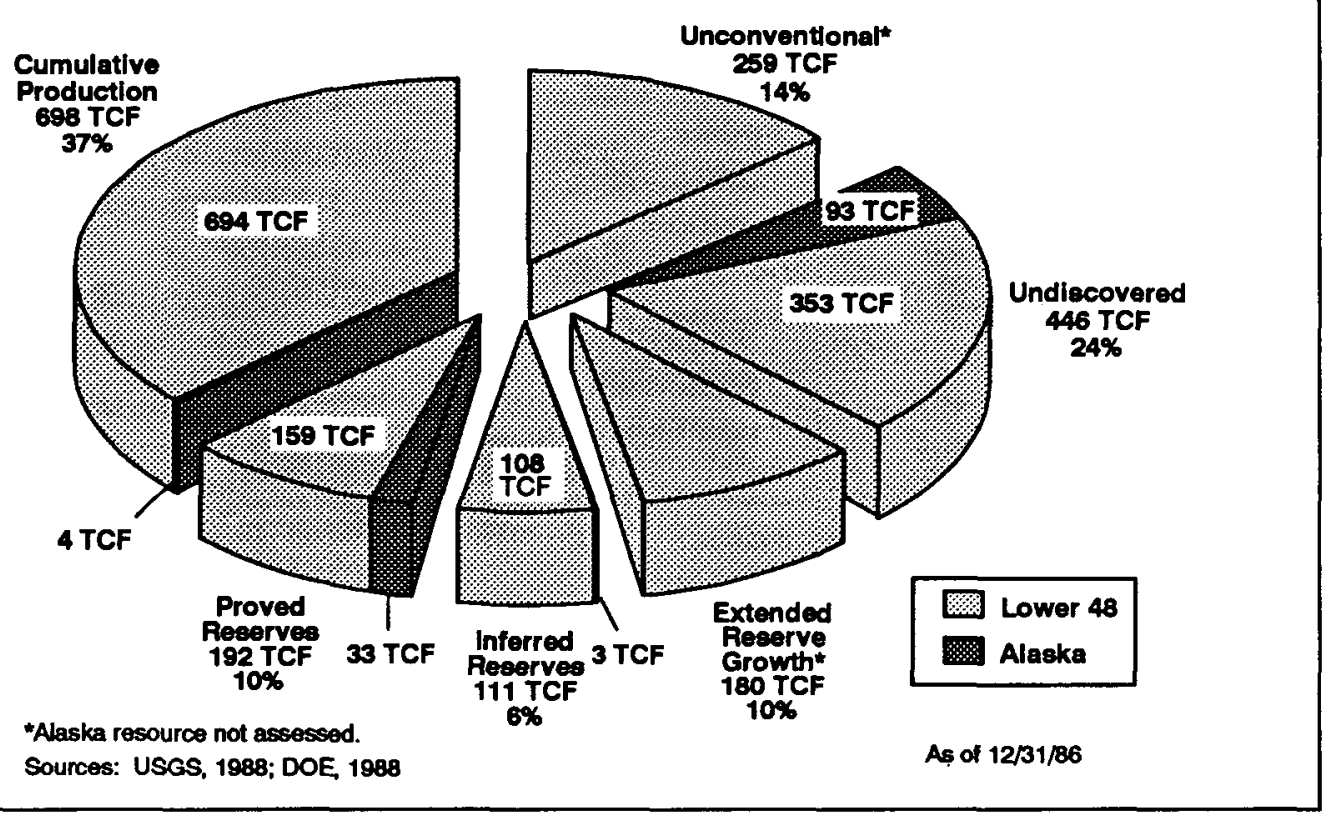

Only a portion of the technically recoverable gas can be expected to be economically converted to reserves (DOE, 1988a). In addition, significant commercial production has not been demonstrated for three gass resources. These are deep source gas, methane hydrates, and geopressured methane. The magnitude of these resources has been estimated in the thousands of Tcf, but large uncertainty exists regarding both the size of the resource and the potential for recovery. Significant production from any of the unconventional gas resources requires advances in techniques for locating, characterizing, stimulating, and producing the gas-bearing formations.

In addition to gas recovery from currently known conventional and unconventional resources, DOE has estimated that almost 450 Tcf can be discovered in new fields if geoscientific methods and economic conditions permit (DOE, 1988a). Of this, more than 90 Tcf lie in Alaska, which imposes additional environmental, transportation and/or marketing constraints.

\section{BARRIERS TO RECOVERY}

In order to convert the nation's oil and gas resources into economically producible reserves, a number of barriers must be overcome. These barriers fall into three categories: technical, economic and institutional/regulatory. While geoscience research contributes directly to overcoming the technical barriers, it can also minimize 
constraints in the other areas by reducing uncertainty and risk and by providing data and analyses that can lead to more informed decision making by government and industry officials.

\section{Technical Barriers}

The single most important technical problem is the current lack of understanding of reservoir architecture and how it affects fluid flow. In most cases, the reservoir, or rock matrix containing the hydrocarbon accumulation, is not homogeneous. Rather, variations in physical and chemical properties exist throughout the structure. These variations (heterogeneities), by controlling fluid flow, determine the degree to which remaining oil and gas can be recovered from the reservoir.

The production of unrecovered mobile oil and immobile oil requires advances in understanding and prediction of heterogeneities and flowpaths in the reservoir and increased predictability and cost-effectiveness of extraction techniques. Mobile oil remains unproduced because it is uncontacted by wells at conventional well spacing or is bypassed by conventional fluid injection at current well spacing. Also, economic oil- and gas-bearing zones may have been bypassed in completing some wells. Immobile oil remains in the reservoir largely because of controlling factors, such as capillary forces, pressure, pore size and configuration, and fluid properties. A need exists for-better injectant materials for enhanced oil recovery and a better understanding of the effects of rock properties, rock/fluid interactions, and natural and artificial fracturing on process performance.

Results of oil recovery projects indicate that where heterogeneities are minimal, advanced extraction processes are predictable; where they are significant, such processes are difficult to control and results are often disappointing. However, the problem goes beyond simply understanding reservoir heterogeneity. At the current state-of-the-art, we do not know how to measure parameter variations over the bulk of the reservoir, or how to incorporate them into effective fluid flow simulations.

Discovery and production of shallow gas and gas associated with oil production must overcome the same technical barriers to recovery as oil. In addition, non-associated gas reservoirs deeper than 15,000 feet present unique difficulties. Conventional geophysical exploratory techniques currently lack resolution at great depth, significantly increasing exploration risk. Beyond the extreme pressure and temperature conditions encountered in drilling and producing these deep reservoirs, understanding of such fundamental geologic factors as reservoir porosity and hydrocarbon maturation associated with deep gas prospects is lacking.

Unique barriers also constrain the recovery of unconventional gas resources. These barriers include: the inability to predict the location of gas-bearing lenses; inadequate understanding and control of fracture stimulation of tight formations; inadequate understanding of the three-dimensional distribution of gas flows, in situ stresses, character of the fracture network, and drainage paths in Devonian shale and other gas-bearing formations; the need for improved methods to determine gas content, water saturation, permeability, and gas producibility in coal seams for coalbed methane; and a requirement for development of improved fracture models to optimize treatment designs.

Production from all of these unconventional resources is constrained by the current lack of quantitative geoscientific description that is necessary for simulation and prediction. Such understanding is the key to developing cost-effective recovery techniques. Other more speculative unconventional gas 
resources, such as gas from geopressured aquifers, gas hydrates, and deep source gas, also present special challenges. The basic nature of these resources must be understood and economic recovery methods must be developed.

\section{Economic Barriers}

The abandonment of currently producing wells, discussed earlier, is essentially an economic problem. Most states (and the federal government on federal lands) require that oil and gas wells be permanently plugged within a short time (from 6 months to 2 years) after the end of economic production in order to prevent groundwater contamination and return control of mineral rights to the mineral owner. More than $65 \%$ of the oil and $40 \%$ of the gas remains on average after conventional recovery. After plugging and abandonment, this resource may not be available for additional production that could result from application of new technology or higher prices, depending on the cost of drilling and completing new wells. The impact of these abandonments becomes even more critical offshore. Geoscience research can develop technologies that use these wells to help recover some of the remaining oil and gas, and can provide plugging techniques that are economically reversible to provide access to these resources through those wells that must be plugged.

Drilling oil and gas wells in unproven fields involves significant economic risk: $76 \%$ of all exploratory wells are dry, while only $21 \%$ of development wells are dry (API, 1990). Operators consider it necessary to spread their drilling capital over as many wells as possible. Therefore, the majority of small operators and many larger companies require other investors as partners in drilling wells. Recent changes in the tax laws have reduced economic incentives to individuals to participate in high-risk drilling ventures. Also, many large companies are shifting exploration efforts to areas outside the U.S. where the probability of major new finds is better and oil can be produced more cheaply. Many of the smaller companies are faced with severe cash flow limitations and simply do not have the resources to undertake the research necessary to address the technical problems. Geoscience research can increase the operators' ability to find oil and gas, thereby reducing risks and costs.

\section{Institutional and Regulatory Barriers}

Various regulatory constraints also present barriers to recovery. For example, most states set rules for the regular spacing of wells, specifically limiting the minimum distance between wells. In a relatively homogeneous reservoir, this has little effect on production. However, in laterally discontinuous reservoirs (as are the majority), this limitation results in isolation of some flow units from others (e.g., uncontacted mobile oil), leaving producible resources untapped. The efficient application of geologic understanding to the location of unrecovered oil and gas will require non-standard spacing of wells.

Traditionally, geologic information has been considered proprietary by most operators, and many states have only recently required that well logs be made public. State governments do not require an operator either to collect or release the complete record of geoscientific information considered necessary to interpret the depositional environments of prospective hydrocarbon producing formations or design enhanced oil and gas recovery projects. Thus, while the proprietary interests of the industry must be recognized, incomplete geoscience information dispersed among many operators will hinder future attempts to analyze oil and gas basins fully and develop additional reserves from known fields.

Environmental concerns associated with oil and gas operations could also create impediments to realizing the productive 
potential of domestic oil and gas resources. Current regulatory initiatives being considered by the Environmental Protection Agency and directed toward oil and gas operations could considerably increase the cost of resource development, and could have significant impact on the economics of developing future energy supplies. Such regulations concern the underground injection of fluids associated with oil and gas production, the disposal of drilling muds, produced water, and other wastes associated with oil and gas operations, and the abandonment of production and injection wells. Research on the characteristics and behavior of reservoirs and aquifers; the transport, fate and effects of injected materials; and the environmental risk associated with abandoned wells can bring needed scientific data to the regulatory debate. 


\section{Chapter 3 \\ GOAL AND OBJECTIVES}

\section{THE STRATEGIC GOAL}

The previous section identified the many and varied needs for hydrocarbon geoscience research which define the issues guiding the development of this strategy. As suggested by these needs, the ultimate goal of the hydrocarbon geoscience research strategy is:

To increase significantly the economic producibility of domestic oil and gas resources through geoscience research and related activities.

Without such a goal, the strategy lacks focus and becomes little more than a collection of interesting investigations. Using this goal, a strategy can be derived for removing the barriers to recovery of oil and gas by conducting research with industry and transferring the results of that research as widely as possible. The goal statement implies a number of important considerations that guide strategy development.

For the reasons stated in the introduction, the goal focuses upon domestic oil and gas resources, both onshore and offshore; other hydrocarbon resources (e.g., oil shale, coal, tar sands) are excluded at this time. This in no way discounts the value of these other resources. This strategy has been devised to have maximum impact on the resources that have been identified as highest priority for geoscience research, namely, oil and gas. These resources are expected to have the greatest potential to contribute to domestic energy needs in the current economic climate. Other resources will be addressed later, as dictated by national priorities.

While the federal government can provide some of the tools leading to increased production of domestic oil and gas resources, the ultimate goal cannot be achieved without industry cooperation and participation. Given the need to work closely with industry to achieve success, the goal stresses economic producibility of oil and gas. The strategy is not intended simply to increase the technically recoverable resource base; instead, it seeks to expand the nation's inventory of economically producible resources. Industry must operate within the marketplace, and those additional reserves must be competitive at world market prices. This does not mean, however, that research on advanced technologies should wait until prices rise enough to make those technologies economic. Research should begin immediately so that technologies will be available when economics warrant their implementation. More importantly, one focus of the research is to lower the costs of advanced technologies to make them economic as soon as possible.

\section{OBJECTIVES}

Several major objectives have been identified that must be accomplished to meet the goal. These objectives address on the resource target and the industry that is expected to produce it once successful $R \& D$ has removed the technical barriers. The timing of the research efforts is key to the successful application of the results. 
Abandonment of current reservoirs may limit economic access to remaining resources. Such access is required to achieve the full recovery potential of advanced technologies. Better understanding of the resource and solutions to recovery problems will follow as current research progresses. For these reasons, the objectives have been grouped into three time frames according to the length of time required for research results to become available and be transferred to producers.

The work toward all three sets of objectives should begin immediately and should be pursued simultaneously. They represent a continuity of effort. Advances achieved toward one set of temporal objectives can be expected to have immediate impact on the others. Similarly, unanticipated problems encountered in pursuing one objective may generate research requirements under other objectives. The strategic objectives are listed below.

\section{Near-Term Objective \\ (Results produced in 5 years or less)}

N.1. Maintain access to the resources in currently producing domestic oil and gas fields, and decrease the rate of decline of domestic production by application of currently available technology.

The strategy for achieving this objective must focus on ways to forestall the abandonment of wells that are needed to gain access to current reservoirs for the economic application of advanced recovery technologies. This includes activities to increase recovery from these reservoirs using currently available methods. This effort should concentrate on the reservoirs that have both high potential for future recovery and high risk of abandonment. This work must be implemented rapidly.
Mid-Term Objectives

(Results produced in 10 years or less)

M.1. Maximize the recovery of discovered oil and gas through improved understanding of the resource and development of advanced extraction techniques.

M.2. Increase the efficiency of resource discovery through improved understanding and advanced instrumentation.

M.3. Expand environmental understanding to keep pace with advances in extraction technology.

An understanding and quantification of reservoir heterogeneities and other resource characteristics is the key to achieving these objectives. This understanding can then be applied to the location and recovery of oil and gas remaining in current reservoirs and to undiscovered and unconventional resource targets. Improved instrumentation, interpretation and simulation will aid in this understanding, while advanced extraction technology will maximize recovery in an environmentally acceptable manner.

Long-Term Objectives

(Results produced beyond 10 years)

L.1. Improve the fundamental understanding of the oil and gas resource and the chemical, physical, and biological phenomena that govern its occurrence and recovery and the environmental impacts of its use.

L.2. Support the community of scientists and researchers in the field of oil and gas discovery and recovery by providing research and training opportunities.

The first objective will be attained through basic and fundamental research into the formation of oil and gas reservoirs and into 
the mechanisms for mobilizing oil and gas in these reservoirs. The longer time frame allows for revolutionary advances in technology to be pursued and developed. Such revolutionary developments may, however, be implemented in a shorter time frame. They can spread rapidly within the research community and can be translated quickly into commercial application, thus having a significant impact on the near- and mid-term objectives. The second objective implies a continuing effort to train and support those who will both develop and apply the research results in the future. 
$$
\text { . }
$$ 


\section{Chapter 4 \\ STRATEGY FOR IMPROVED OIL AND GAS \\ DISCOVERY AND RECOVERY}

\section{CONSIDERATIONS IN STRATEGY DEVELOPMENT}

The previous sections have shown that the national problems of oil and gas production are severe, the magnitude of the resource available for their solution is considerable, and the barriers to be overcome in converting these opportunities into reserves and production are significant -- significant enough to demand a goal and objectives that are ambitious and comprehensive. The strategy to meet the goal and objectives must be correspondingly ambitious and comprehensive. Before addressing the individual objectives, therefore, several considerations that apply across the entire strategy need to be discussed.

\section{Resource Focus}

The strategy concentrates on the specific problems of specific resources having the greatest potential for adding to the nation's reserves. Thus, the strategy calls for systematic evaluation and selection of the components of the resource (reservoirs, geologic classes of reservoirs, formation types, etc.) with the greatest potential to respond to technology advances.

This implies a slightly different emphasis for each time frame. Research aimed at achieving the near-term objective must concentrate on the parts of the resource which are most threatened by abandonment and which have the greatest potential for recovery by available or nearly available techniques. Research under the mid-term objectives should focus on resources with the greatest ultimate potential for recovery by advanced techniques. Long-term research should target the parts of the resource that, not being amenable to currently hypothesized advanced technologies, would yield the largest gains from revolutionary advances in technology or discovery of new exploration frontiers. While the different objectives may focus on different parts of the oil and gas resource, it should be reemphasized that the research will be conducted in parallel and that results in one area may have significant impacts on research in the other areas.

Once the high priority resources have been identified, the concrete problems of specific resources become the focus of the research activities (See Figure 4.). If the immediate problem to be solved by research is to overcome production barriers, the requirements of that solution are inherent in the geological, engineering, and institutional characteristics of that particular resource. In most cases, the solution to the problem will require an interdisciplinary approach to the concrete issues of the specific resource.

\section{Integration Across Objectives}

While it is logical and convenient to organize the strategic objectives according to the time frames in which research products will be produced, the strategy requires substantial program integration across the objectives. For the strategy to achieve its goals, this integration will necessarily take a number of different forms.

- The analyses and decision making that establish the priorities among resources across the three time frames must proceed from a common base of data, assumptions, 
Figure 4

Overview of DOE Geoscience Research Strategy

Time to

Availability

of R\&D

Results

Present

5 years

-10 years

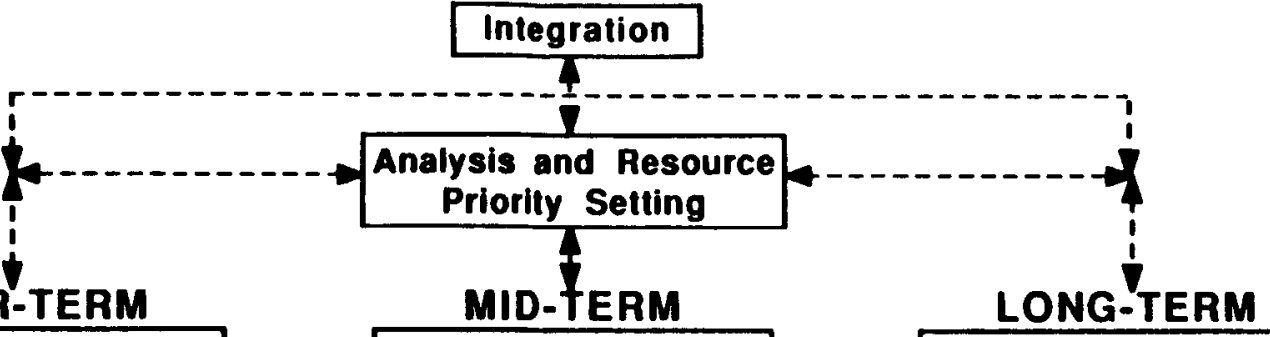

NEAR-TERM

OBJECTIVE: Maintain access.

PRIORITY

RESOURCE: Urgent and economic.

TECHNOLOGY: Known, currently available.

- Apply existing reservoir

characterization

technology

- Apply existing

production stratogies

- Generalize to similar

reservoirs

- Develop reversible

plugging techniques

- Promote technology

transier

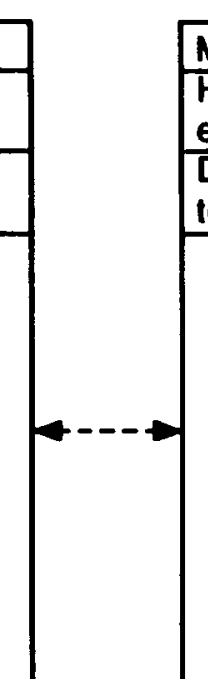

Maximize recovery.

High potential and

economic.

Defined advanced

technology.

- Validate reservoir

class theories

- Heterogeneity

description

- Generalization of

theories

- Apply theories to

- Mobile oil and gas

-- Immobile oll

.. Unconventional gas

- Improve instrumentation

and inferpretation

- Improve performance

prediction tectniques

- Increase discovery

efficiency

- Pertorm basin analysis

- Improve environmental

understanding of

advanced technology

impacts

- Promole technology

transfer

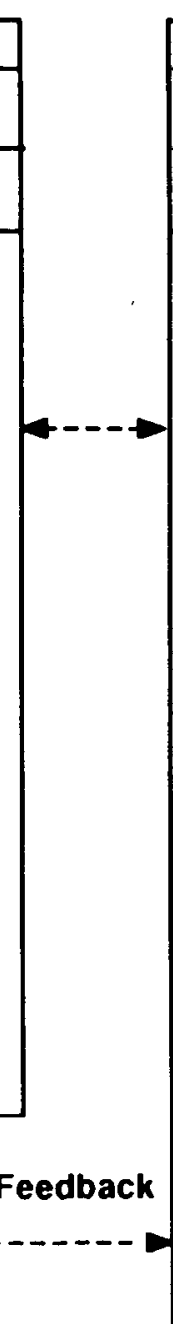

Improve understanding

Not amenable to mid-term advanced technology.

Not yet delined.

- Conduct sustaining

discipline-oriented research

.- Heterogeneity and

permeability studies

- Underground

imaging

- Research drilling

- Ground water and

contaminant transport

- Conduct supporting mission-oriented research

.- Reservoir and lluid

properties

- Physical constraints

to recovery

- Innovative extraction

methods

- Perform advanced basin analysis

- Support the research

community

- Promote technology

transfer
To Integration

and Analysis

Priority Selting
Monitoring, Evaluation, and Feedback

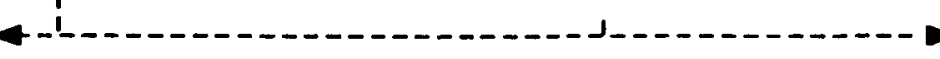


and criteria. For example, the priorities for near-term research will be based, in part, on the resource potential that results from projected success in achieving mid-term objectives.

- Close interaction among research activities conducted under the respective time frames is necessary. Even initial progress on mid-term or long-term objectives could affect near-term success or failure, and research results in any of the temporal objectives could stimulate reappraisal of priorities as new technical constraints and opportunities are identified by research results.

- Integration is needed across the resources to generalize fully the results or methods that may be discovered so they may be applied as widely as possible.

The need for such integration imposes requirements for information collection, reduction, interpretation, and flow. A critical aspect of the detailed program planning to implement this strategy will be to define responsibilities for these tasks and for the decision making that makes use of the information.

\section{Technology Transfer}

The strategy uses specific operator problems in specific reservoir settings as a basis for the design of research activities. The strategy also must address ways to transfer the newly developed technologies and methodologies to the oil and gas operators -both non-integrated and integrated companies. Non-integrated companies are smaller and therefore have smaller research staffs (if any) and modest capabilities. With an aggressive technology transfer program, these companies are likely to benefit most from focused research. Technology transfer activities will have to be modified to address the specific audiences applicable to the research hardware and procedures. In many cases, technology transfer will take the form of workshops or seminars to introduce the newly developed products or use other means to address the wide variability in operator types and support organizations. This topic is discussed more fully in Chapter 5 .

\section{Monitoring, Evaluation, and Feedback}

Monitoring and evaluation of research results (i.e., the extent to which the problems are being solved), and feedback to the strategy are explicitly included in the strategy. Monitoring of field results against established performance objectives will feed back into the design of the research activities and could cause revisions in program priorities. Improved understanding of measurement, interpretation, or production technologies could well result in revisions to the strategy or its detailed implementation.

\section{Economic Assumptions}

Finally, note that the strategic goal emphasizes economic producibility of oil and gas. This necessitates that a projection of oil and gas prices be kept in mind when developing a strategy. The assumption throughout this document is that oil and gas prices will follow a path similar to current DOE projections, and will increase at a moderate rate, without a significant price rise or fall (EIA, 1990a). This defines the economic situation faced by the industry that will apply the results of the program. However, if significant, unexpected economic changes do take place, the strategy and its implementation will be modified accordingly. Such changes would be expected to affect the timing of research needs and applications. 


\section{STRATEGY FOR ACHIEVING THE NEAR-TERM OBJECTIVE}

When a well is permanently plugged, economic access to the remaining oil and gas associated with that well may also be abandoned, depending on the costs of redrilling, future oil prices, and the legal status of the leasehold. The oil and gas left behind includes any resource in penetrated zones that remain uncompleted ("behind pipe") due to failure of past and current detection efforts.
This significantly increases the cost of new recovery techniques that might be applied to that reservoir because of the need to drill more new wells than would otherwise have been required. This will make those techniques uneconomic in many cases under projected prices. Therefore, the near-term objective is:

\section{N.1 Maintain access to the resources in currently producing domestic oil and gas fields, and decrease the rate of decline of domestic production by application of currently available technology.}

This is clearly the most significant and critical of all the objectives, for unless the rate of abandonment is reduced, economic access to much of the remaining resource may be lost until oil prices increase significantly. Once access is lost, results of mid- and long-term work will have fewer places for application. Although the issue is currently more critical in the case of oil, recent work indicates that it applies to natural gas as well.

Preserving economic access to the reservoirs, consequently, is a crucial part of the strategy. Compiling and evaluating data on abandonments, and closely coordinating this information with the directions in research is also critical. Technical evaluation from the mechanical and engineering perspective as well as from the geoscientific perspective must occur. This would allow assessment of the types of reservoirs penetrated by the wells, the condition of the wells, the risk of abandonment, and the remaining resource associated with the wells. It would also permit evaluation of those reservoirs at risk of abandonment in terms of potential recovery from current and advanced technologies, and identification of potential bypassed hydrocarbon-bearing zones. Participation by industry will be essential to this process.
Thus, the first aspect of the near-term strategy is to:

\section{N.1.a Identify those producing fields with significant potential for additional resource recovery and risk of being abandoned as a function of time.}

This effort would result in a risk/potential ranking of the major reservoirs presenting clear priorities for research. This is the critical step because it defines the problem in concrete technical terms and permits the work to be focused on specific issues that can have the most impact. The resource recovery potential will be evaluated for the application of both current technology and advanced recovery techniques as a function of time and oil price. Without this knowledge base, the program may pursue good technical work that has insignificant impact. The results will also permit a better structuring of much of the mid-term effort.

As work on the first part of the strategy proceeds, work should begin on the identification and application of current technologies that can help maintain access to high-priority targets. The rate of decline of domestic oil and gas production, exacerbated by low oil prices, can be slowed by applying existing technology for reservoir 
characterization and production. Application of known concepts of internal reservoir architecture and lateral continuity of reservoir units, along with existing data collection and production technologies, will allow operators to target specific technologies to be applied in specific situations, i.e., targeted infill drilling, completion of additional pay zones, stimulation treatments, profile modification, and well integrity evaluations, to improve production from existing operations.

Even though concepts and technologies are known or "currently available," it does not necessarily follow that they are widely accepted or applied. Many technologies are applied only in specific geologic or geographic conditions, or by certain segments of the industry, although they could be much more widely applied. Also, some technologies are just advancing past the laboratory phase and are becoming commercially available, while still others were developed for other purposes but show significant potential for oil and gas discovery and recovery. Identifying the potential of these concepts and technologies and accelerating their dissemination in pursuit of national objectives is within the federal role.

This leads to the second strategic element under this objective:

\section{N.1.b Identify existing information sources and demonstrate existing reservoir characterization technologies applicable to infill drilling and secondary and tertiary recovery techniques.}

DOE can assist in the communication of known data and concepts about reservoir architecture by providing mechanisms for discussion and demonstrations of economic techniques of reservoir characterization. This will facilitate information flow between the oil and gas operators and service companies, and state geological surveys, universities, consulting scientists, and national labs. Use of previously successful programs, such as locally specific workshops and field trips for operators and cost-shared field demonstrations, would rapidly transmit the results of completed research. The Oil Recovery Technology Partnership between the petroleum industry and the national labs is one example of an existing component of this strategy.

To complement this effort, a third strategic element should be pursued:

\section{N.1.c Identify existing production strategies that are (or could be) successfully employed in high-risk, high-potential reservoirs, and assure widespread dissemination of the technology.}

Having identified the reservoirs with the greatest potential and the highest immediate risk of abandonment, economic production options for maintaining them need to be pursued. An approach to this would be to compile state production reports by basin for operations in reservoirs of similar geologic types that are not at risk, i.e., still economic, and determine through engineering analysis the extent to which the technology can be used in high-risk situations. This review would be used in combination with a detailed engineering and geological analysis to identify additional recovery techniques that could be economically applied to reduce the risk of abandonment. Technology transfer to operators with similar situations should occur in parallel, using local producer organizations and field service companies to establish technology transfer and familiarization workshops to assure that all operators are aware of the options.

This effort should begin as soon as good candidate situations are identified. It should be modified as work in the mid-term efforts produces results in improved reservoir typing that permits a more informed prioritization and risk/benefit analysis of producing 
properties. This near-term effort will also produce estimates of continued operating life by reservoir type for use in guiding the work on mid-term advanced extraction technologies.

The above work, if successful, will have the added benefit of helping to maintain the current infrastructure of skilled people, companies and equipment required for the production of oil and gas. The ability to produce oil and gas relies on a viable, active producing infrastructure that can respond to future changes in the energy supply situation. Without this infrastructure, the implementation of more sophisticated advanced recovery processes will be difficult, at best.

As technologies are being applied in specific reservoir settings, the impact of this objective can be increased through a fourth strategic element:

\section{N.1.d Apply known information about reservoir architecture, reservoir continuity, and production strategies to similar or adjacent reservoirs, providing rapid expansion of current technology to a broad spectrum of known resources.}

DOE can contribute to the rapid application of known geoscience concepts and recovery technologies to reservoirs not previously characterized by supporting cost-shared demonstrations by experienced institutions with existing data bases. This is part of the technology transfer function described earlier and must be designed to address a wide variety of resource types and industry segments.

For those situations where no economic alternative to plugging can be found, a fifth strategic element can provide assistance:

\section{N.1.e Provide geoscientific information to assist in the development of environmentally sound alternatives to plugging wells with cement.}

To preserve access to the resource in reservoirs that are near their economic limit but are not amenable to extending production by currently available technologies, research is needed to develop and demonstrate environmentally sound, cost-effective ways to avoid well plugging with cement. Techniques must be developed to delay the plugging and abandonment of idle or temporarily abandoned wells. Where there is no alternative to plugging, environmentally safe, economically reversible plugging technology could serve as a fallback. These methods may include the use of alternative materials to cement for sealing the well bore. This work would have to be closely coordinated with the Environmental Protection Agency (EPA) and state agencies.

Geoscience research can also help identify areas subject to high environmental risk, thereby aiding the definition of technical and regulatory needs. For example, oil and gas reservoirs prone to casing corrosion, high pressures or other completion problems may be at high risk of aquifer contamination or other environmental problems. Geoscience research can provide data to support technical solutions and regulatory decisions aimed at operating these fields in an environmentally safe manner while maintaining economic access to the resource.

Table 1 lists some important research areas that address the near-term objective. This research must be closely coordinated with the activities under the mid-term objectives, as discussed in the next section. 
Research Topics for the Near-Term Objective

$\underline{\text { Research Topic }}$

Resource Assessment

Resource Characterization

Production Strategies

Plugging Alternatives

Technology Transfer

\section{Description}

Analysis and ranking of producing reservoirs in terms of risk of abandonment and future production potential to serve as a guide to research priorities.

Engineering, geologic and geophysical characterization of reservoir rocks and fluids sufficient to locate and quantify oil, gas, reservoir brines, and major heterogeneities involving matrix porosities, permeabilities, lithologies, fractures, and fracture orientation.

Identification of options for maintaining and increasing production in high-risk/high-potential reservoirs.

Engineering, geological, and environmental research to develop new/modified alternatives to plugging with cement for future, inexpensive reopening of access to the resources; and research to identify and address areas of high environmental risk.

Identification of resource-specific operator problems in high-risk, high-potential fields as guidance in targeting research activities; and development of new methods and techniques to transfer successful research to the oil and gas industry for implementation. 


\section{STRATEGY FOR ACHIEVING THE MID-TERM OBJECTIVES}

The mid-term objectives for improved oil and gas discovery and recovery are not only the continuation and enhancement of the near-term objective but also increased research on the complex recovery technologies that are necessary to produce the oil and gas. The near-term objective focuses on geoscience research to maintain economic access to current reservoirs and disseminate current concepts in geological and engineering characterization and production strategies. The mid-term objectives address improved methods for locating and quantifying oil and gas resources, and the development of advanced extraction technologies for efficient, economic production of oil and gas. This first mid-term objective is:

\section{M.1 Maximize the recovery of discovered oil and gas through improved understanding of the resource and development of advanced extraction techniques.}

Variability in reservoir characteristics that affect fluid flow limit the producibility of mobile oil and gas; viscous and capillary forces trap oil and maintain it in an immobile state. In the past, attempts to understand discontinuities and recover these resources have been made on a reservoir-by-reservoir basis with only a very limited ability to extend what was learned to other situations. It has become increasingly clear that better knowledge and understanding of the reservoir factors affecting fluid flow are required before increased production from the known resource base can be achieved.

The influence of reservoir characteristics on natural gas flow is also of fundamental importance, but the relevant characteristics differ somewhat from those that control the flow of oil. For example, the role of adsorption and desorption can be important in the movement of gas, as is the relative permeability between gas and water. Since non-associated natural gas will normally be found at greater depths than oil, the effect of lithostatic pressure on reservoir properties can also be a significant issue in the producibility of gas.

The extrapolation of reservoir characteristics to groups of similar reservoirs is a critical step in achieving widespread use of advanced recovery technologies. Thus, the first element of the mid-term strategy is:

\section{M.1.a Evaluate and verify current theories based on the hypothesis of reservoir class.}

The concept of "reservoir class" states that reservoirs with similar geologic histories will have similar internal consistencies and inconsistencies (heterogeneities) and, thus, exhibit similar fluid flow behavior (BEG, 1986). This hypothesis has been demonstrated in a limited number of cases and, if it can be shown to apply to a representative spectrum of domestic hydrocarbon accumulations, it offers the best hope of dealing effectively with the remaining oil and gas resource. Simply stated, a viable theory would allow the results of detailed work in a specific reservoir to be extended with confidence to others of the same class.

The basic strategy to be followed requires detailed analysis of existing data and grouping of reservoirs according to their geologic and production histories, creating a catalogue of classes. Using these data, it should be possible to identify those classes which have the greatest potential for recovery enhancement and to select representative sites for detailed work based upon available data and operator willingness to cooperate and 
participate. The effort would also attempt to determine the location of remaining oil and gas, whether mobile or immobile, and develop physical explanations for the observations. Using these results, predictions could then be made and tested in other members of the class. Through comparison of predicted and actual results, the classification procedures could be refined and retested to develop a more reliable predictive capability.

These theories would be both applied and verified in cooperation with industry (with cost sharing) in the next step:

\section{M.1.b Apply the resulting theories to the location and production of bypassed and uncontacted mobile oil and gas.}

Increased production of mobile oil and bypassed gas is a high priority target. These are the resource targets most likely to be viable under current economic conditions and their production extends the operating life of reservoirs that would otherwise be abandoned.

Based on the work described above, it would be possible to develop a series of cost-shared projects to demonstrate the wide applicability of two critical technological innovations: geologically targeted infill drilling and fluid flow profile modification. Targeted drilling would recover uncontacted oil and gas by selectively placing wells to penetrate compartmentalized reservoir areas, and would use fewer wells to contact non-compartmentalized reservoir areas. It would also reduce the amount of bypassed oil and gas by using the optimum economic well spacing. Fluid flow profile modification would reduce the amount of bypassed oil by more completely sweeping the reservoir in waterflooding operations. Each project would address a specific reservoir type with high resource potential for maximum impact as research results are transferred to other reservoirs.
At the same time, the strategy would:

\section{M.1.c Apply the theories to the production of remaining immobile oil.}

The near-term effort and the work on remaining mobile oil can be expected to maintain operations in many fields that would otherwise be abandoned. This buys time for the development and verification of advanced extraction technologies involving the injection of steam, chemicals, or gases to recover part of the immobile oil. Research in this area would include the development of improved injectants with properties that improve oil recovery in a wider range of reservoir types, improved predictability and control of process flows in reservoirs, and characterization of rock and fluid properties and rock/fluid interactions. Integration of the mid-term efforts is important since the same reservoir parameters that affect the flow of mobile oil will have an impact on the flow of injectants and other fluids that are part of advanced recovery processes.

\section{M.1.d Apply the theories to the production of unconventional natural gas.}

The term unconventional gas, as used here, includes gas from low-permeability formations such as shales, coal beds, and tight sandstones, and gas from geopressured aquifers. Additional and more speculative unconventional sources include gas from depths greater than normally drilled $(>25,000$ $\mathrm{ft}$.), and gas hydrates. While each of these sources has potential for future contribution to the U.S. energy supply, only the tight-formation gas and methane from coal seams are likely to contribute large quantities during the mid-term time scale considered here.

Assuming a valid classification scheme exists for tight reservoirs, the crucial need in connection with this resource will be for advanced extraction technology. Advanced 
rock fracturing technology, economic horizontal drilling technology, and new methods for predicting and delineating naturally fractured zones at reservoir depths will be key to the full exploitation of this resource.

In the case of coalbed methane, parameters such as coal depth, thickness, rank, and gas content will be needed as input to any classification scheme. With this information in hand, experiments for testing various extraction techniques can be developed.

The oil and gas efforts described above are targeted at specific resource problems. In parallel with this work, more basic scientific work would be required to improve the understanding, measurement, and interpretation of reservoir heterogeneity and architecture, and how they affect fluid flow. Research that applies across the spectrum of resources is needed in two areas:

\section{M.1.e Develop advanced instrumentation and interpretation methods.}

Even with past advancements in geoscience technology, our knowledge base is inadequate concerning the origin, composition, structure, and processes of the continental crust. In dealing with hydrocarbon resources, our basic geoscientific comprehension and measurement capabilities are still inadequate for prediction at the more restricted regional and local scales normally encountered in exploration and production operations. A necessary condition for accurate prediction of oil and gas producibility is a detailed description of the reservoir, its architecture, heterogeneities, and internal flowpaths, that is qualitatively and quantitatively accurate. Construction of such a description is largely beyond present capabilities because of limitations in both measurement and interpretation. A substantial amount can be determined through qualitative interpretation of the reservoir's geological history, but synthesizing a useable quantitative description requires additional information. Much of the measurement of reservoir properties is indirect (e.g., well logging) and complex (e.g., three-dimensional seismic), requiring advanced mathematical conversion for interpretation of reservoir properties. Reinterpretation of previously collected data could be a cost-effective approach in many areas because collecting raw data can be costly, but this requires advanced computational and interpretive techniques. Further, the data are often sparse (e.g., wells separated by tens or hundreds of acres), vastly different in scale (e.g., microscopic porosity to megascopic structure), and changing in different parts of the reservoir. Advanced geological interpretation, scaling, and geostatistical techniques must be created, verified, and synthesized to generate the required reservoir descriptions.

Considerable work in this area is already being performed, but its beneficial impact would improve with increased focus on the same high priority reservoir classes identified in the work outlined above. Having specific requirements with matching test sites should focus the effort more effectively.

\section{M.1.f Develop advanced reservoir performance prediction techniques.}

Accurate and economical reservoir simulation techniques will be needed to enable the strategy to complete the cycle of theory development, prediction, and testing that is necessary for the realization of predictable, controllable, advanced extraction technologies. This work is intimately dependent upon advances in the mathematical description of reservoirs and their heterogeneity described above, but goes beyond to predict the behavior of the extraction process as it operates in the reservoir. A number of reservoir simulators exist which, with simplifying assumptions, are adequate in certain reservoir settings and for certain recovery techniques. In more complex 
reservoirs, however, predictive accuracy is inadequate.

Work in this area must proceed, supporting both industry and academic efforts, along two fronts. The first is to exploit and anticipate the ever-expanding capabilities of newer, faster, and more powerful computers. This could permit an explicit, simultaneous treatment of the internal flowpaths, heterogeneities, and processes at increasing levels of detail and precision. While this approach can directly contribute to the validation of the theories and interpretations of reservoir structure and performance, the cost and level of sophistication can limit its applicability. The second approach is to develop new algorithms that accurately incorporate the essence of the more detailed approach but that can be implemented on smaller, lower-cost computers. These more accessible models can be developed from and validated against the more detailed simulators, but both must be tested by comparing their predictions to field results. Once validation establishes the accuracy of such models, they can be used to design and evaluate cost-effective, controllable oil and gas extraction processes. This level of advancement can most readily be achieved by focusing on the specific requirements of the high priority reservoir classes addressed in the work described above.

The private sector currently expends considerable efforts in the area of reservoir simulation. Continued advances in this field, particularly in the ability to predict the performance of advanced technologies, should be encouraged by DOE.

The second mid-term objective is:

\section{M.2 Increase the efficiency of resource discovery through improved understanding and advanced instrumentation.}

Advances made in understanding reservoir classes and hydrocarbon formation and accumulation should be applied to resource discovery. Any broadly applicable theory or research product that improves finding rates for oil and gas will certainly improve domestic productivity and lower production costs. The intent, however, should be consistent with the federal role in this highly competitive area. This role is limited to providing technical information to industry for use in their search for oil and gas.

Another research area that can provide valuable information for increasing industry exploration efficiency, as well as contributing to an overall understanding of the nation's oil and gas resource, is multidisciplinary basin analysis. Since the turn of this century, spurred largely by the search for oil and gas, the study of sedimentary basins has evolved into a systematic, multidisciplinary science. Early explorationists relied principally on field sampling and mapping at the level of a few square miles. The concept of folded rock strata, overlain by sediments, served as the model for geologic interpretations. The modern explorationist can, and does, explore on basin-wide scales. All aspects of basin evolution are addressed, including basin subsidence and infilling, compaction, thermal history, and stress history. The integration of many disciplines provides new insight into the resource potential of a basin. In addition, factors which affect large regions within a basin, e.g., geologic history or distribution of rock layers, are often well beyond the scope of investigation of a company operating in an individual reservoir or field. Exploration at large scales has been greatly aided by advances. in remote sensing techniques, deep crustal seismic techniques, and a variety of other geological, geophysical and geochemical techniques. 
As mature as this specialty has become, much relevant research remains to be done. Basin analysis involves the integration of not only the geological and engineering disciplines, but also basic science elements in mathematics, physics, chemistry, and computer technology. Such research would require participation by, and close coordination among, all the federal agencies represented on the HGRCC, as well as universities, consultants, and service companies.

As work toward the first two objectives progresses, it will also be important to pursue efforts under the third objective.

\section{M.3 Expand environmental understanding to keep pace with advances in extraction technology.}

Advances in extraction technologies should be pursued with a thorough understanding of the environmental consequences of the application of these technologies. Technology application will be limited where threats to the environment are real or perceived. The monitoring of potential but unforseen environmental impacts should be included in all research associated with advanced or novel extraction technologies. For example, there is a need to understand the transport, fate and effects of injected materials. Both the users of such technologies and the public at large must be made aware of the environmental consequences and tradeoffs associated with their application.

In addition, the work in instrumentation and interpretation techniques discussed earlier should be applied to assure environmental issues are addressed. Advances in techniques to identify areas subject to environmental risk from drilling and production operations will be required. For example, low-cost tools for measuring fluid movement behind the casing in existing wells, without ceasing operations to make the measurements, could help monitor environmental impacts without greatly affecting the current costs of operation. DOE and EPA cooperation in this type of research could result in the development of technologies that meet both environmental protection and energy supply objectives.

Table 2 shows examples of research areas needed to accomplish the mid-term objectives. High priority should be placed on advanced characterization and quantification of the reservoir heterogeneities that play a dominant role in contacting and recovering the known resource. Successful research in this area supports further advances in targeting needed instrumentation, interpretation approaches, theoretical concepts, simulation capabilities, specialized extraction technologies, and statistical methods for assessing the producibility of the undiscovered resources.

\section{STRATEGY FOR ACHIEVING THE LONG-TERM OBJECTIVES}

Because of the urgency associated with oil and gas production, work supporting both the near-term and mid-term objectives will be based upon the best information available. However, our current understanding of the geoscientific processes that control the accumulation and movement of hydrocarbons in the subsurface is limited. Work in the longer term can address the critical uncertainties inherent in the shorter-term efforts. But this effort must go beyond simply addressing well-defined practical problems. Where the shorter-term efforts stress the interdisciplinary approach, the longer term will provide the more discipline-specific research that is so vital to meeting the goal. The 


\section{Research Topics for Mid-Term Objectives}

$\underline{\text { Research Topic }}$

Validate Reservoir Class

Theories

Heterogeneity

Characterization

Advanced Resource

Characterization

Advanced Extraction

Technologies

Simulation Methodologies

Advanced Instrumentation and Interpretation

Technology Transfer

Basin Analysis

\section{Description}

Evaluation and verification of theories of reservoir class to allow results of work in one reservoir to be extended to other reservoirs.

Characterization and quantification of the heterogeneities that play a significant role in resource recovery.

Characterization to locate and quantify the resource, estimate the significant resource characteristics, and understand and control flow of fluids through the reservoir.

Research to alleviate and overcome reservoir heterogeneities that complicate the extraction of oil and gas; to characterize rock and fluid properties and their interactions; and to predict and control process performance.

Encouraging the development of reservoir simulators that more accurately match production performance and predict recoveries of oil and gas. Includes models for use on advanced computers as well as simplified models for use on less sophisticated systems.

Instrumentation and data interpretation to locate and quantify the resource and reservoir heterogeneities in known and undiscovered reservoirs, monitor fluid flow during injection of fluids, and aid in defining additional quantities of oil and gas in non-producing zones in known reservoirs.

Identification of resource-specific operator problems in high-risk, high-potential fields as guidance in targeting research activities; and development of new methods and techniques to transfer successful research to the oil and gas industry for implementation.

Research to characterize the geologic formations in key U.S. producing basins to serve as a guide to exploration potential, development strategies and resource assessment. Identify promising areas of basin-wide research suggested by the development of advanced technologies and innovative theories. 
insights gained here will provide valuable input to the shorter-term activities. This work is also anticipated to seek out and develop novel ideas and new approaches for dealing with the subsurface processes occurring within the geologic framework.

The first long-term objective is:

L.1 Improve the fundamental understanding of the oil and gas resource and the chemical, physical, and biological phenomena that govern its occurrence and recovery and the environmental impacts of its use.

The long-term effort is, by necessity, broad and extremely challenging. The strategy for achieving this objective includes two complementary parts: sustaining basic research in relevant scientific disciplines, and supporting mission-oriented basic research.

In sustaining basic research, the emphasis will be placed on the various geoscience disciplines. Because of the enormous breadth of these activities, continuing review and input will be sought from leading experts in industry, universities, federal laboratories and other federal agencies. Their help will come mainly through established advisory committees and scientific workshops where major requirements are identified and prioritized. Priorities will be further defined by reviewing results of research under the near- and mid-term objectives. DOE will then implement the suggestions within the context of program priorities and available technical expertise and resources. Individual experts may also be asked to review particular proposals and grant applications. The selection process stresses not only the relevance to technical objectives but also creativity and scientific excellence within the context of the discipline.

This process, along with feedback from the nearer-term efforts, will lead to the recognition of specific problems needing urgent resolution. These problems form the basis for the second category, mission-oriented basic research. The nearer-term efforts will address applied research approaches; the long-term efforts will, as an alternative, seek revolutionary solutions with more far-reaching application. The focus of this effort will be the enormous oil and gas resources remaining in the ground after currently envisioned advanced recovery technologies have been applied. Research will be needed to determine basic reservoir and fluid properties and the physical constraints that restrict oil and gas recovery, and to develop innovative ways to overcome those constraints. For example, new injectant materials could be developed to alter rock or oil properties for more efficient, economic production. Inherent in the research program is the concept of maintaining a small pool of resources to support new concepts received through the unsolicited proposal and grant application routes. In addition, opportunities will be sought to take advantage of ongoing federal research projects by conducting additional data collection and testing, e.g., in deep oil, gas or geothermal wells, in pursuit of the long-term objectives.

The second long-term objective is:

\section{L.2 Support the community of scientists and researchers in the field of oil and gas discovery and recovery by providing research and training opportunities.}

The programs for achieving the long-term objectives have a unique technology transfer requirement. The human resources of the oil and gas industry are scientists and engineers working on the discovery and recovery of oil and gas in field service companies, operating companies, and state agencies, and the students, scientists, and engineers who will be 
involved in the next generation of research and development. The latter group: is of prime concern in meeting this objective. A substantial fraction of the basic research is done by post-doctoral research associates and graduate students, who transfer newly developed ideas and techniques into future career activities.

Educational opportunities are also provided by making national facilities available to researchers. The major DOE research facilities are attracting increasing interest from the geoscience research community, including the oil and gas industry.

Several studies of long-term research needs have been conducted and are now serving as a basis for current activities. These studies have identified many important research requirements. One example is a recommendation for a research program to map the physical properties of rock at reservoir depths with the goal of improving resolution from the current 100 meters to one meter. This is a very ambitious goal. Related matters of reservoir heterogeneity and permeability studies have also been identified as high priority concerns. Improvements in reservoir modeling are critically dependent on better quantification of the distribution of permeability as well as defining the geometry and architecture of the reservoir.

Finally, a strong program integration function is as critical here as with the rest of the program. Analysis of progress made against near- and mid-term objectives can reveal gaps in the fundamental understanding of specific phenomena, leading to the development of requirements for vitally needed basic research. Advances in the fundamental understanding of physical phenomena must be evaluated for application to results obtained from other work.

Examples of major research topics relevant to long-term oil and gas objectives are shown in Table 3.

\section{BENEFITS AND RESERVES TARGETS}

The decline in production of oil and gas may be slowed or halted by reserve additions due to timely and effective improvement and transferral of the needed geoscience technologies. Estimating the quantities of such reserve additions amid the present uncertainties represents a formidable task; indeed, the reduction of many of these key uncertainties will be an important product of the research. Currently available studies, however, can be used to define and estimate the reserves targets that would be associated with success of the geoscience R\&D strategy. Actual conversion of these targets to reserve additions will depend not only on $R \& D$ and technology transfer success, but also on future economic, policy, and regulatory conditions.
Reserve additions that could result from successful completion of geoscience research objectives are substantial. Development of estimates of these targeted reserves and the remaining resources requires assumptions that the technologies to be improved or developed: can be described in engineering detail today and demonstrated and transferred to operators in a timely fashion; are economic at oil prices of $\$ 20 / \mathrm{bbl}$ (or $\$ 3 / \mathrm{Mcf}$ ) or less in the near-term and $\$ 32 / \mathrm{bbl}$ (or $\$ 5 / \mathrm{Mcf}$ ) in the mid-term; are not inhibited by regulatory policy; and can be implemented by the then-available industrial infrastructure (DOE,1990). The long-term research target is to further improve recovery by increasing the understanding of the remaining resource target. Under these broad assumptions, the future reserve additions without geoscience research and the target 
Table 3

Research Topics for Long-Term Objectives

$\underline{\text { Research Area }}$

Underground Imaging

Heterogeneity and

Permeability Studies

Hydrocarbon Research Drilling

Ground Water and

Contaminant Transport

Origins of Oil and Gas

Basin Analysis

Advanced Recovery

Technologies

\section{Description}

Map rock properties at reservoir depth with a resolution of one meter.

Develop a fundamental understanding of reservoir heterogeneity, microstratigraphy, and fluid flow in porous and fractured media.

Study reservoir characterization, sequence stratigraphy and crustal geology, obscured terrains, and frontier and underexplored areas through a program of scientific drilling.

Advance the understanding of the environmental consequences of oil and gas production by fundamental research of the geochemical and microbiological processes and the properties of subsurface sediments and aquifers that control the fate and movement of energy-related contaminants.

Examine physical and chemical processes and environments that convert biological materials to oil and gas. Include detailed examination of subsurface environments that lead from organic source material to accumulations of oil and gas in reservoirs.

Apply innovative technology and novel concepts to basinwide research.

Develop innovative processes to overcome constraints to oil and gas production by altering reservoir rock and fluid properties to achieve more efficient, economic recovery. 
reserve additions attributable to the success of the strategy can be estimated (Figure 5).

- In the absence of this initiative in geoscience research, 27 billion barrels (BBbl) of oil and 339 trillion cubic feet (Tcf) of gas are projected to be added over several decades to the nation's current proved reserves, the largest component of which are statistically inferred growth in known fields and new discoveries.

- Meeting the near-term objectives of the geoscience strategy would forestall abandonment of marginal wells and accelerate use of existing technologies where applicable. Collectively, these are estimated to add about $15 \mathrm{BBbl}$ of oil reserves. While this oil could be made economically and technically recoverable within five years given success in these objectives, the actual development of these reserves is expected to take longer. Natural gas resources associated with oil reserve growth, which could also be preserved by success in meeting near-term objectives, are estimated at 17 Tcf; while natural gas liquids associated with the production of this gas would total $1 \mathrm{BBbl}$.

- In achieving the mid-term objectives, advances in reservoir description and increases in oil prices could lead to reserve additions of up to $81 \mathrm{BBbl}$ of oil $(61 \mathrm{BBbl}$ of mobile and immobile oil and $20 \mathrm{BBbl}$ of undiscovered), $4 \mathrm{BBbl}$ of natural gas liquids, and 415 Tcf of gas, with the largest contributions being made by immobile oil recovery from known fields $(39 \mathrm{BBbl})$ and unconventional gas recovery $(218 \mathrm{Tcf})$. Although these technologies are expected to be available within 5 to 10 years, a longer period would be needed to fully prove these reserves.

- Cumulatively, success in meeting the nearand mid-term objectives has the potential of adding nearly four times as much oil and nearly twice as much gas as the reserve additions expected in the absence of the $R \& D$ advances proposed here.

- Meeting these objectives will still leave a massive resource, a target for further technology advances or oil prices over $\$ 35$ per barrel. While current studies have not assessed the recovery potential from these oil and gas resources, principally due to the lack of defined processes for their economic extraction, their size alone indicates the importance of meeting long-term research objectives. This resource represents over $350 \mathrm{BBbl}$ of remaining oil and more than $400 \mathrm{Tcf}$ of technically recoverable gas. Recovery of any sizable portion of this resource will rely on production processes not yet demonstrated, even in the lab, requiring an aggressive basic $R \& D$ program to develop, test, and implement projects in the field.

Targets are cumulative in the sense that failure to meet near-term objectives may reduce the mid- and long-term benefits if well abandonments restrict access to the resource remaining in the reservoir.

Despite the uncertainties surrounding these estimated reserve and remaining resource targets, they are undeniably large, representing potential solutions to the major national energy problems which inspired the development of this strategy. But, while the potential targets are huge, they are realistic in light of the opportunities suggested by the magnitude of the domestic resource. The estimates assume full success of the strategy but disregard major breakthroughs that could convert additional, remaining resources into reserves or any major advances in the recovery of deep gas, methane hydrates, or geopressured methane. Thus, while uncertain, the estimates are so large that, even if substantially reduced by the resolution of uncertainties, they would remain significant contributions to the national energy wellbeing. 
Figure 5

DOE Geoscience Research Strategy Targets Significant Reserve Additions

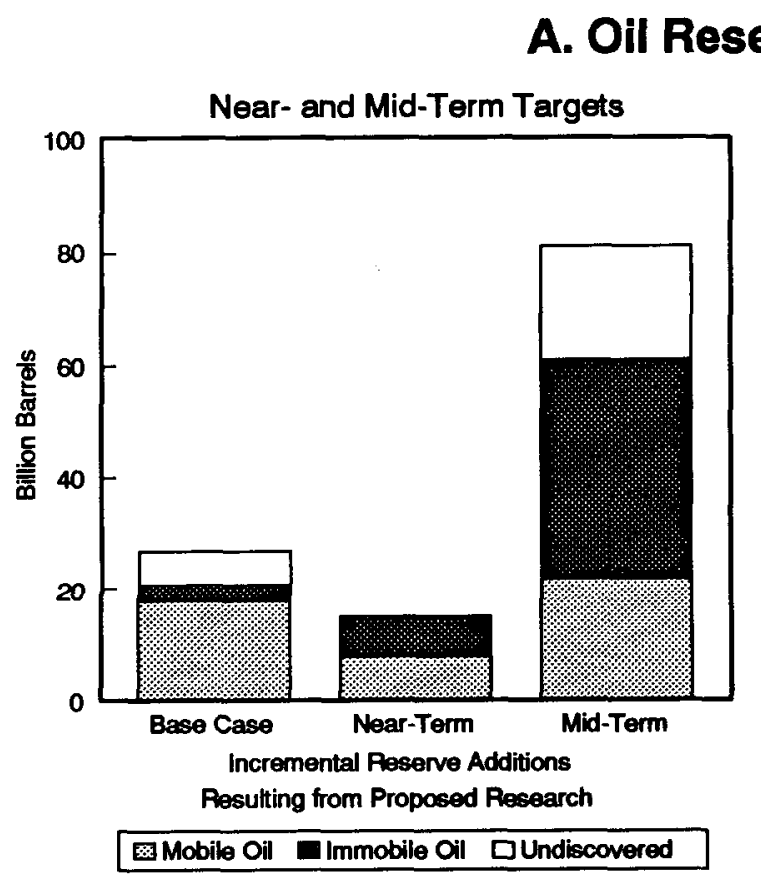

Long-Term Remaining Resource in Place Target

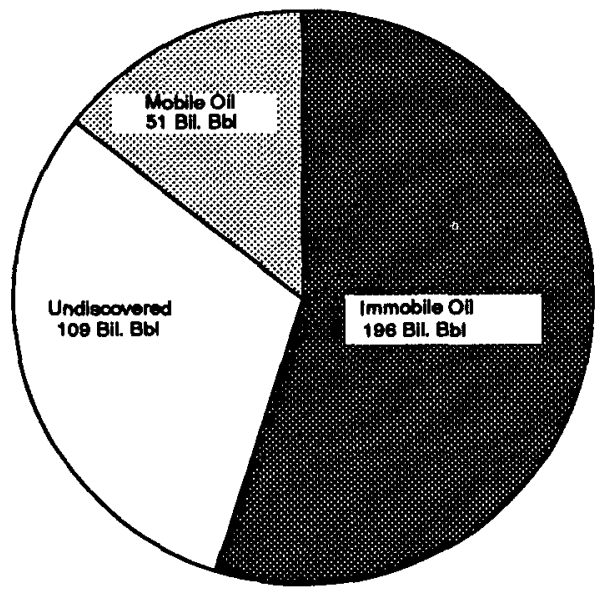

Total Long-Term Target: 356 Bil. Bbl

\section{B. Gas Research Targets}

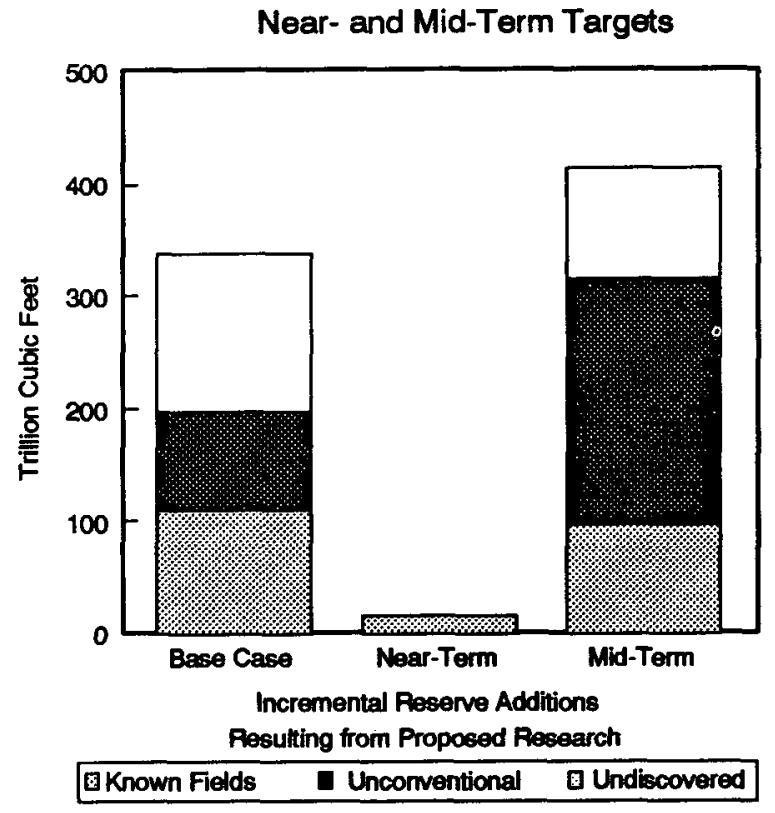

Long-Term Technically Recoverable Resource Target

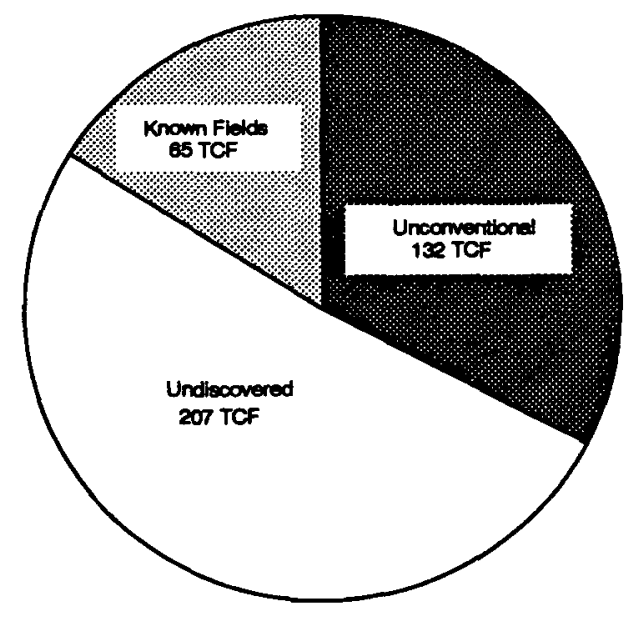

Total Long-Term Target: 404 TCF 


\section{Chapter 5 \\ TECHNOLOGY TRANSFER}

Inherent in this strategy is an aggressive technology transfer effort. Its objective is to get program results in a timely and efficient manner to those who can most effectively use them. The requirements for technology transfer have many elements in common across the three time frames, but each also has its own unique criteria. While it is an integral part of the strategy, technology transfer is of sufficient importance that a separate, more detailed discussion is warranted.

In order to be successful, the program must incorporate the needs of the target audience -- the "customer" for its products -- in two major ways. First, the nature of the technical problems faced by.industry should be a driving factor in the design of the research program and the activities undertaken in that program. Second, the program must deliver its results and products quickly and effectively to the customer in a way that will lead to their acceptance and use.

To address the first aspect of technology transfer, the sectors of the industry that are relevant to each objective and the technical barriers that they face must be identified. 'These barriers depend on the nature of the resource as well as the characteristics of the industry segments, e.g., major oil and gas companies and large and small independent operators, that are trying to find and produce the resource. This will be assured by industry participation in defining the research problems and the high-priority targets. By involving industry from the beginning and directing the research toward solving their problems, the federal program will have a higher probability of producing useful results.
Once research results are achieved, they must be communicated, not only to operators but to the consultants and service companies with whom the operators work and to other researchers who will build on those results. In general, the standard and proven technology transfer techniques based on publications, workshops, and technical meetings will continue to serve all three temporal efforts in reaching the most sophisticated audiences. This group includes public and private researchers and the technical staffs of the larger production companies. The HGRCC will assure that the needed transfer occurs within the Department.

A special effort will be required in the near-term where the goal is to maintain access to reservoirs with large future production potential. Activities associated with acquainting smaller producers with production options not familiar to them will require considerable innovation. Fortunately, precedents are available. The experience gained in the early 1950 s when the Bureau of Mines Bartlesville Laboratory (now part of DOE) was active in transferring waterflooding technology in the mid-continent is particularly relevant. Other examples include the current Office of Fossil Energy work with the Interstate Oil Compact Commission on a series of regional meetings designed to familiarize small producers with recent developments, and the Oil Recovery Technology Partnership in which national laboratories are making available to the oil and gas industry relevant technologies that have been developed under other federal programs (e.g., underground imaging methods developed for defense programs). Additional approaches could include computer software that could be easily used by small operators, 
and oil and gas extension services which would provide experts to discuss operator problems in the field and suggest solutions. These methods can also be used to disseminate the products of mid-term research as they become available.

The target audience for the near-term effort is quite diverse. It includes smaller producers, the field service companies and engineering consultants that support them, various state agencies, and financial institutions. The former groups can be reached through local meetings held in cooperation with the various independent producer associations and, possibly, state geological surveys. Where applicable new technology can be exploited, DOE would develop and make available methods that would permit a small operator the opportunity to evaluate his property at little or no cost. Operators would be expected to deal with service companies or consultants for actual engineering and implementation. In the case where a demonstration project would be undertaken, or where an operator with an ongoing successful project would cooperate, case histories would be developed for presentation, and other operators who may be able to use the process would be encouraged to make site visits.
State agencies also have unique technology requirements. Most regulation is based upon the situation that existed in the early days of the oil industry, and many regulatory programs should be reviewed. Questions of well spacing and unitization, for example, are more likely to be reviewed when new data are available. Information products will have to be designed to meet this need. Recent DOE support of the IOCC study of state incentives for EOR is an example of successful technology transfer. Technical information supplied by DOE was used by the IOCC to evaluate the potential for tertiary oil recovery in New Mexico, Oklahoma, and Texas. As a result of this work, legislation was passed in Oklahoma to provide incentives that should encourage new production.

Financial institutions, who may be called upon to finance new projects, also have special information needs, and products must be designed to meet them. Working through local producer associations, it will be possible to contact these institutions and work with them to provide research products that fulfill their needs. 


\section{Chapter 6 \\ APPROACH TO IMPLEMENTATION}

The strategy described in this document enhances the focus of hydrocarbon geoscience research within the Department. DOE's fiscal year 1991 budget request to Congress and future year budget projections reflect changes consistent with this strategy. The first step in the implementation of this strategy must be the development of implementation plans by the program offices within DOE, coordinated through the HGRCC. These plans will be organized according to the missions of the individual offices and in many cases will address geoscience activities as a component of a larger program. They will describe specific research activities needed to implement the strategy and develop research products that will help achieve the strategic objectives. The plans will contain schedules, milestones and budgets and will be reviewed within the Department before being released to industry and the research community for information and feedback. These plans, along with this strategy, will be used in the DOE annual budget development to justify and prioritize budgets for geoscience research. In some cases, an intermediate step may be required to describe how geoscience activities fit into the overall program mission and structure.

The critical role of the implementation plans will be the translation of the strategic objectives into concrete actions. This process will require the assignment of priorities to the variety of activities that could be undertaken in each research area. This will be done by assessing the contributions the activities can be expected to make toward the strategic goal and objectives. The validity of these priorities will be assessed through regular evaluation of the research products and progress toward achieving the objectives.
The strategy will be implemented by the DOE organizations described in the "DOE Geoscience Program Overview" section, with appropriate participation by other federal agencies. Briefly, the Office of Fossil Energy conducts fundamental and applied research on the development of technologies to characterize and extract oil and gas resources. The Office of Energy Research conducts basic, discipline-oriented research in the geosciences. Other DOE program offices, such as the Office of Conservation and Renewable Energy, the Office of Nuclear Energy, and the Office of Civilian Radioactive Waste Management, conduct geoscience research activities as part of their specific missions (Appendix B). Some of these activities are applicable to hydrocarbon resources and will be identified and coordinated through the HGRCC.

Other federal agencies that have important hydrocarbon geoscience research missions include the U.S. Geological Survey (USGS), the Minerals Management Service (MMS), and the National Science Foundation (NSF). These agencies are represented on the HGRCC. The USGS conducts basic geoscience research and, together with MMS, conducts programs for hydrocarbon resource assessment. The NSF funds basic research in geoscience disciplines. Through the HGRCC, their activities will be coordinated with the DOE programs, and both DOE and the other agencies will be made aware of research relevant to their respective missions.

Implementation of this strategy will involve a mix of public and private research and development organizations. The national laboratories offer a broad range of capabilities in such areas as computer modeling and 
instrumentation. The university community offers outstanding research talent as well as the cadres of graduate students whose training in energy research will be needed in the future. The state geological surveys have expertise in local and regional geology, and may have the best data on the resource and industry activity within their respective states. The USGS and MMS can be expected to play an important role where the scale of investigation exceeds state boundaries and opportunities exist for joint activities. Finally, private industry must be at the core of the program and the $R \& D$ planning and must participate in as many activities as possible if meaningful technology transfer is to take place. Where appropriate, the Department should encourage groups of companies, industry organizations, State and Federal organizations, universities, and consultants to join together in R\&D consortia based on their shared interest. This consortium mechanism can provide a means for participants to leverage their resources, and may serve as a shared R\&D infrastructure for companies too small to have their own research departments. This will provide an immediate transfer of technical know-how to the participatig members of the target segment of the industry. An aggressive technology transfer program will assure that the results of the research are widely disseminated to operators and support organizations that do not participate directly in research projects.

In order to aid in implementation and track progress, the HGRCC will form subcommittees composed of program managers to address high-priority research areas. These subcommittees will review the current DOE programs for compatibility with the strategy. This will involve identifying gaps in research areas that address the objectives and opportunities for enhancement of ongoing programs. Unnecessary duplication of activity among programs will also be identified and eliminated. The subcommittees will recommend changes in program direction and additional research that should be undertaken for consideration by the HGRCC. Finally, they will help evaluate the progress of the research programs toward the stated goals and objectives.

A critical part of the implementation of the strategy will be monitoring, evaluation and feedback. Progress of the programs will be monitored by the program offices in terms of the research products being developed and transferred to industry, and the successful application of those products to produce oil and gas. This progress will be reported to the HGRCC for incorporation into its annual report. Evaluation should be made both on the specific issue of whether the research solved the particular problem it was designed to address, and on the broader issue of whether the overall program is effectively achieving the objectives. The results of this evaluation will be used by the program managers to redirect individual research efforts and program directions where needed.

Finally, both the implementation plans and the strategy will be updated regularly. The implementation plans will be revised yearly to incorporate research progress, new budgets, and revisions to the strategy. The strategy will be updated biennially to incorporate the results of program evaluations, industry developments, changing economic and policy considerations, and the need to address additional hydrocarbon resources. 


\section{REFERENCES}

(API, 1990)

(API/AGA/CPA, 1980)

(BEG, 1986)

(Commerce, 1975-89)

(DOE, 1987a)

(DOE, 1987b)

(DOE, 1988a)

(DOE, 1988b)

(DOE, 1989a)

(DOE, 1989b)

(DOE,1990)

(DOI, 1987)

(EIA, 1989a)
American Petroleum Institute, Basic Petroleum Databook, January 1990.

American Petroleum Institute/American Gas Association/Canadian Petroleum Association, Reserves of Crude Oil, Natural Gas Liquids and Natural Gas in the U.S. and Canada as of 12/31/79, June 1980.

Finley, Robert J. and Tyler, Noel, Bureau of Economic Geology, "Geological Characterization of Sandstone Reservoirs" in Reservoir Characterization, edited by Lake, Larry W. and Carroll, Herbert B., Jr., Academic Press, 1986.

U.S. Dept. of Commerce, Statistical Abstract of the United States, 1975-1989.

Department of Energy, Energy Security, March 1987.

Department of Energy, Energy Research Advisory Board, Geoscience Research for Energy Security, February 1987.

Department of Entergy, An Assessment of the Natural Gas Resource Base of the United States, May 1988.

Department of Energy, Producing Unrecovered Mobile Oil: Evaluation of Potential Economically Recoverable Reserves in Texas, Oklahoma, and New Mexico, December 1988.

Department of Energy, Bartlesville Project Office, Abandonment Rates of the Known Domestic Oil Resource, November 1989.

Department of Energy, Office of Fossil Energy, Federal Oil Research: R\&D to Maximize the Producibility of Known U.S. Oil, August 1989.

Department of Energy, Office of Fossil Energy, Federal Oil Research Program Implementation Plan, Draft, January 1990.

Department of the Interior, Arctic National Wildlife Refuge, Alaska, Coastal Plain Resource Assessment, April 1987.

Energy Information Administration, Annual Energy Review 1988, May 1989. 
(EIA, 1989b)

(EIA, 1990a)

(EIA, 1990b)

(Geoscience Institute, 1989)

(IOCC, 1989)

(NPC, 1987)

(OGJ, 1989)

(USHR, 1988-89)

(USGS, 1981)

(USGS-MMS, 1988)

(USGS-MMS, 1989)

(World Oil, 1988)
Energy Information Administration, U.S. Crude Oil, Natural Gas, and Natural Gas Liquids Reserves, 1988 Annual Report, October 1989.

Energy Information Administration, Annual Energy Outlook, 1990. Energy Information Administration, Monthly 'Energy Review, November 1989, published February 1990.

Major Program Elements for an Advanced Geoscience Oil and Gas Recovery Research Initiative, conducted by Geoscience Institute for Oil and Gas Recovery Research on behalf of U.S. Department of Energy, Office of Fossil Energy, October 1989.

Interstate Oil Compact Commission \& National Stripper Well Association, National Stripper Well Survey, January 1989.

National Petroleum Council, Factors Affecting the U.S. Oil \& Gas Outlook, February 1987.

Oil and Gas Journal Energy Database, 1989 Energy Statistics Sourcebook, 1989.

U.S. House of Representatives, H.R. 4967, House Report 100-862; H.R. 4867, House Report 100-713; H. Con. Res. 268, House Report 100-658; H.R. 4505, House Report 100-636; H.J. Res. 395, House Report 100-498; House Report 101-264.

United States Geological Survey, Estimates of Undiscovered Recoverable Conventional Resources of Oil and Gas in the United States, Circular 860, 1981.

United States Geological Survey-Minerals Management Service, National Assessment of Undiscovered Conventional Oil and Gas Resources, Open File Report 88-373, 1988.

United States Geological Survey-Minerals Management Service, Estimates of Undiscovered Conventional Oil and Gas Resources in the United States -- A Part of the Nation's Energy Endowment, 1989.

World Oil, 43̂rd International Outlook, August 1988. 


\section{Appendix A}

\section{CHARTER \\ DEPARTMENT OF ENERGY (DOE) \\ HYDROCARBON GEOSCIENCE RESEARCH \\ COORDINATING COMMITTEE (HGRCC)}

The HGRCC is a committee of the DOE reporting to the Under Secretary for DOE.

\section{Purpose}

The purpose of DOE HGRCC is to: (a) achieve more effective coordination of all hydrocarbon geoscience research and development; (b) be responsible for developing an integrated strategic plan for hydrocarbon geoscience research activities within the Department; (c) assure implementation of an integrated, comprehensive program covering DOE hydrocarbon geoscience programs to ensure that the short and long-term hydrocarbon geoscience research needs of the country are identified and appropriately supported; (d) prevent unnecessary duplication, promote coordination and cooperation of hydrocarbon geoscience research, and coordinate hydrocarbon geoscience research with other government agencies, industry, and universities; (e) assure optimum use of DOE's existing expertise in the field of hydrocarbon geoscience research and development; and (f) achieve the most rapid communication among DOE program representatives of new developmencs, opportunities and problems in hydrocarbon related geoscience.

Hydrocarbon geoscience research is defined as research and development activities directed toward the discovery and recovery of hydrocarbon resources especially in oil and gas. Specific topical areas for inclusion or exclusion shall be recommended by the
Committee. Particular emphasis in the basic research area is placed on those topics interacting with applied efforts although it is recognized that all basic research in hydrocarbon geoscience is not immediately relevant to the applied programs. In the development programs, emphasis is placed on hydrocarbon geoscience development, hydrocarbon geoscience engineering and technology transfer.

II. Responsibilities

A. Exchange of program, budgetary and planning information: HGRCC members shall keep their respective organizational personnel informed of pertinent information concerning other organizational programs so as to avoid duplication of effort.

B. Technical Information Exchange: Members of the Committee shall provide and receive information to keep informed of the state of research and technology in hydrocarbon geoscience.

C. Interdepartmental Coordination: HGRCC shall review and evaluate geoscience research activities being conducted by other government agencies, industry, and universities that are relevant to DOE program objectives in order to prevent unnecessary duplication, promote coordination and cooperation of hydrocarbon geoscience research. 
D. Evaluation: HGRCC shall identify areas for increased emphasis or areas of opportunity as the need arises; or respond to requests from the industry, universities, government agencies, the Secretary, Deputy Secretary, Under Secretary, Assistant Secretaries, or Director of Energy Research. HGRCC shall report annually to the Under Secretary with an administrative report and a separate technical report compiling DOE hydrocarbon geoscience programs.

E. Reporting: HGRCC shall keep minutes of each meeting and circulate them to all appropriate entities. HGRCC or its members shall report on its activities as the need arises to Office or Division Directors. When appropriate, the Committee may bring certain hydrocarbon geoscience related matters to the attention of the Under Secretary of DOE.

\section{Membership}

HGRCC shall include members from any DOE organizational unit having a substantial interest in hydrocarbon geoscience.

The Secretarial Officer of each organizational unit represented on the
Committee shall designate a member of his staff to be a member of HGRCC. Each Secretarial Officer organization shall have one vote. The Secretarial Officer may designate other non-voting members. Such Committee members will serve as the principal point of contact for Committee matters and shall be responsible for arranging for the participation of other staff of the organizational units concerned, as appropriate.

\section{IV.Officers}

The HGRCC shall have a Chairman and an Executive Secretary to carry out the administrative functions of the Committee. Consistent with Fossil Energy's Mission Area Assignment, the Chairman shall be the Assistant Secretary for Fossil Energy or his designee. The Executive Secretary need not be a member and shall be appointed by the Chairman.

\section{Meetings}

The Assistant Secretary for Fossil Energy shall determine the frequency of meetings which shall be not less than quarterly. The Assistant Secretary for Fossil Energy shall determine the time of day, place, and agenda for meetings.

\section{OFFICE OF GEOSCIENCE RESEARCH}

$\underline{\text { Mission }}$

The Office of Geoscience Research (OGR) is responsible for developing and administering strategic plans to ensure that the hydrocarbon geoscience research needs of the energy industry and FE programs are identified and appropriately supported. While all non-FE geoscience research is to be pursued within the cognizant program offices and the Office of Energy Research, the OGR's mission is to integrate the program strategies and research of various $F E$ and
DOE organizations in order to feed knowledge into the development of recovery models and strategies. The Office is the focus of hydrocarbon-related geoscience research and the focal point within DOE as the advocate and coordinator of the program.

\section{Functions}

- Develops policy and program strategy for all Geoscience Research programs to achieve objectives established by the ASFE or directed by national energy policy. 
Designs, directs and reviews analyses of overall FE program strategy and development of new techniques for the evaluation of long-term geoscience research implications.

- Manages and directs Hydrocarbon Geoscience Research Coordinating Committee activities.

- Oversees all hydrocarbon geoscience research activities within FE. Evaluates ongoing programs to prevent unnecessary duplication, promote coordination and cooperation of hydrocarbon geoscience research, and coordinates hydrocarbon geoscience research with other Government agencies, industry and universities.

- Assures implementation of an integrated, comprehensive program covering DOE hydrocarbon geoscience research. Assures hydrocarbon geoscience research needs of the country are identified and appropriately supported.
- Advises the ASFE on all matters related to hydrocarbon geoscience research and assures that he is aware of any new or changing policies, technologies or issues that may impact the FE Hydrocarbon Geoscience Research Program.

- Responsible for the transfer of geoscience technology among federal, state, universities and private sector organizations to ensure that all information is available to all interested parties.

- Deals with top level representatives of major U.S. and foreign corporations and governments in the implementation of the Hydrocarbon Geoscience Research Program.

- Serves as the focal point for coordination of FE's Hydrocarbon Geoscience Research Program. 


\section{Appendix B}

\section{PROGRAM MISSION STATEMENTS}

\section{OFFICE OF FOSSIL ENERGY}

The Assistant Secretary for Fossil Energy is responsible for managing the Department's fossil fuels research and development programs (i.e., coal, oil and natural gas), the Clean Coal Technology program, Geoscience Research programs, the Strategic Petroleum Reserve, the Naval Petroleum and Oil Shale Reserves, and the Liquefied Gaseous Fuels Spill Test Facility.

The Office of Fossil Energy conducts geoscience research as part of six programs. These programs, and their major geoscientific thrusts are:

- Advanced Extraction and Process Technology: Conducts fundamental research relevant to recovery of oil, gas, oil shale, tar sands, and underground coal gasification to develop a fossil energy-related knowledge base that will improve the economics of fossil fuel production.

- Enhanced Oil Recovery: Conducts research to develop a better understanding of the mechanisms and behavior of advanced and innovative processes for the recovery of presently unrecoverable light oil, heavy oil, and tar sand resources.

- Unconventional Gas Recovery: Develops advanced technologies for the extraction of natural gas from the currently unrecoverable portion of gas resources, including lenticular tight gas sands, Eastern Devonian shales, gas hydrates, and deep source gas.

- Oil Shale: Conducts research to overcome the economic and environmental constraints to industrial development of U.S. oil shale resources.

- Naval Petroleum and Oil Shale Reserves: Produces and conserves the oil, gas, and shale resources contained in these federally owned deposits.

- Strategic Petroleum Reserves: Constructs and operates the nation's emergency oil stockpiles.

\section{OFFICE OF ENERGY RESEARCH}

Under its program in Basic Energy Sciences, the Office of Energy Research supports DOE's central fundamental research activities in the geosciences. The objective of the Geoscience Research activities is to develop a quantitative, predictive understanding of the energy-related aspects of geological processes, focusing primarily on the geophysics and geochemistry of rock/fluid systems, and including increasing emphasis on high resolution underground imaging. Other topics emphasized include geochemical migration, basic geoscience studies of sedimentary formations where oil and gas are located, and Continental Scientific Drilling (to study underground heat and mass transport). 
Under its program on Health and Environmental Research, the Office of Energy Research supports fundamental research to resolve long-term problems related to subsurface contamination from waste disposal at DOE sites. Interdisciplinary research on the properties of groundwater systems that control contaminant transport is conducted. Priorities include the microbiology of subsurface sediments and aquifers to depths of 2000 feet. Also studied are physical-chemical processes such as the influence of mineral and organic colloids on contaminant movement. Process-related research in organic-metals, organic chemical mixtures, and organic-radionuclides is conducted, with attention to the degradation, mobilization and stabilization of these chemical co-contaminants. Emphasis is given to experiments where geochemical and microbial processes operate simultaneously. A national network of field sites is used by university-national laboratory research consortia to conduct the research.

\section{OFFICE OF CONSERVATION AND RENEWABLE ENERGY}

The Office of Conservation and Renewable Energy under its Geothermal Energy Program, seeks to lessen the nation's dependence on foreign energy supplies by fostering the use of indigenous, uninterruptible sources of geothermal energy. This goal of improved energy security is accomplished by developing technology needed to exploit a wide variety of geothermal resources. Such technology enables the unencumbered, competitive use of geothermal energy by the private sector. To the extent practicable, the program emphasizes $\mathrm{R} \& \mathrm{D}$ activities whose costs are shared with the private sector. These activities include the joint development of instruments, equipment, materials, techniques, models, and systems; they provide a ready means of rapid, efficient technology transfer. By employing a strategy that couples applied R\&D with timely technology transfer, the program enhances the security and flexibility of the nation's energy markets.

The Geothermal Energy Program consists of applied R\&D directed toward producing significant, economic energy supplies from the four geothermal resources: hydrothermal, geopressured, hot dry rock, and magma. Topical research areas relevant to these resources include reservoir technology, hard rock penetration, and energy conversion. Each element of the program is governed by one or more quantitative $\mathrm{R} \& \mathrm{D}$ objectives whose cumulative impact will produce a reduction in the cost of energy. The resultant numerical cost objectives provide the basis for planning and managing the program.

\section{OFFICE OF CIVILIAN RADIOACTIVE WASTE MANAGEMENT}

The Office of Civilian Radioactive Waste Management (OCRWM) is responsible for the development of a waste management system for high-level radioactive waste and spent nuclear fuel. The current focus of OCRWM is the establishment of a geological repository for permanent disposal of the waste. Yucca Mountain was designated by Congress in 1987 as the site to be characterized to determine its potential as a repository.

As a part of this site characterization process, a great deal of basic and applied geoscience work is being done under the guidance of OCRWM. This work is being carried out primarily under OCRWM's Office 
of Facilities Siting and Development. Some samples of the topics to be examined at Yucca Mountain are: its geology (three dimensional geologic model, seismology, and volcanism studies); its hydrology (groundwater flow, regional hydrological system, fluid flow in unsaturated zones); meteorology and climate (paleoclimate studies and possible climate changes); geochemistry (mineralogy, petrology, and chemistry of transport pathways and hydrochemical characterization of the unsaturated zone). More than one hundred of these studies are currently planned, many of which relate directly to the geosciences.

\section{NUCLEAR ENERGY - SEISMIC TECHNOLOGY DEVELOPMENT}

Ground motion must be defined for each power plant in order to analyze and design structures to withstand resulting seismic loads in combination with other loads, pressures, and transient temperatures.

Nuclear Energy supported the preparation of a Seismic Technology Program Plan, DOE/SAN-1001, during 1987 and 1988. A team consisting of seismic experts and engineers from universities, national laboratories, and nuclear industry worked for over a year in studying and preparing this plan. In it, the team identified the highest priority elements in seismic technology that would result in the largest benefits to safety and cost of advanced nuclear plants.

Two of these elements involve tasks to improve ground motion definition. Geoscience, including seismology, is involved. Seismically isolated powerplants and standard plant design, the two elements, each require extensive work on earthquake ground motion definitions. Current methods for arriving at and defining ground motion may be inadequate because many important parameters of seismic ground motion are not factored into plant analysis and hence damaging loads and forces may be unduly conservative.

Geoscience studies, involving examination of earthquake records, site geology characteristics and, for some sites, examination of petroleum industry drilling and seismic records, can lead to clearer definition of fault structures and tectonic characteristics which can help improve input motion definition.

There can be a beneficial linkage between the geoscience elements of Nuclear and Fossil programs through the exchange of data and the facilitation of access to data.

Currently, the Department of Energy/Nuclear Energy seismic program is active in two areas:

- Seismic Isolation Bearing Tests at the Energy Technology Engineering Center.

- Development of computer programs for the analysis of seismic isolators and isolated plants at the Argonne National Laboratory.

\section{OFFICE OF DEFENSE PROGRAMS}

The Assistant Secretary for Defense Programs (ASDP) directs the nation's nuclear weapons research, development, testing, production, and surveillance programs. In addition, the ASDP manages the production of special nuclear materials, the Safeguards and Security Program to provide accountability and physical protection of special nuclear materials, the Inertial Fusion research program, and the analysis and coordination of 
international activities related to nuclear technology.

Geosciences concerns associated with Defense Programs responsibilities include:

- Drilling and tunneling operations associated with the emplacement and safe execution of underground tests of nuclear explosive devices.
- Geoscientific studies related to the safe disposal of wastes generated by defense programs.

- Seismology related to the measurement of shock waves caused by underground explosions, as a method for detection of nuclear tests conducted by other nations and for monitoring compliance with treaties imposing limits on underground nuclear testing.

\section{U.S. DEPARTMENT OF THE INTERIOR, UNITED STATES GEOLOGICAL SURVEY}

The mission of the U.S. Geological Survey (USGS) is to provide geologic, topographic, and hydrologic information that contributes to the wise management of the nation's natural resources and that promotes the health, safety, and well-being of the people. This information consists of maps, data bases, and descriptions and analyses of water, energy, and mineral resources, land surface, underlying geologic structure, and the dynamic processes of the earth.

To accomplish its mission, the USGS:

- Conducts and sponsors research in geology, hydrology, mapping, and related sciences to address national needs.

- Produces and updates geographic, cartographic, and remotely sensed information in graphic and digital forms.

- Describes the onshore and offshore geologic framework and develops an understanding of its formation and evolution.

- Assesses energy and mineral resources, determines their origin and manner of occurrence, and develops techniques for their discovery.
- Collects and analyzes data on the quantity and quality of surface water and ground water, on water use, and on the quality of precipitation.

- Assesses water resources and develops an understanding of the impact of human activities and natural phenomena on hydrologic systems.

- Evaluates hazards associated with earthquakes, volcanoes, floods, droughts, toxic materials, landslides, subsidence, and other ground failures.

- Participates in the exploration of space by characterizing processes and materials within the solar system.

- Publishes reports and maps, establishes and maintains earth-science data bases, and disseminates earth-science data and information.

- Provides scientific and technical assistance for the effective use of earth-science techniques, products, and information.

- Coordinates topographic, geologic, and land-use mapping, digital cartography, and water-data acquisition. 


\section{U.S. DEPARTMENT OF THE INTERIOR, MINERALS MANAGEMENT SERVICE}

The Minerals Management Service (MMS) is responsible for offshore minerals leasing and lease management under the provisions of the Outer Continental Shelf (OCS) Lands Act and other related statutes. In implementing the Federal Oil and Gas Royalty Management Act, the Mineral Leasing Act, the Indian Mineral Leasing Acts, and other related statutes, the MMS is also responsible for the collection and distribution of mineral revenues owed to the government and states from federal onshore and offshore mineral leases and to Indian tribes and allottees from many leases on Indian lands.

The major missions of the MMS leasing and royalty management programs are:
- Manage the leasing of oil and gas and other minerals on offshore areas under the jurisdiction of the U.S. Government.

- Classify and evaluate the energy and nonenergy mineral resources of those areas.

- Supervise mineral exploration, development, and production operations pursuant to federal offshore permits and leases.

- Collect and distribute revenues due the federal government, states, and Indian tribes from onshore and offshore mineral leases on lands under federal jurisdiction or Indian lands.

\section{NATIONAL SCIENCE FOUNDATION, EARTH SCIENCES DIVISION}

The National Science Foundation has been charged with advancing several different but interrelated major objectives:

- Accomplishment of basic research.

- Accomplishment of applied research in selected areas.

- Long-term maintenance and strengthening of potential to both basic and applied research in the future.

For applied research, utility and relevance to national objectives are of paramount importance. These criteria are considered during assessment of every proposal with particular stress on improving technology, technology assessment, and policy analysis. Scientific merit and long-term scientific potential, the factors of greatest importance in basic research, are never neglected when assessing applied research proposals. The distinction, in fact, becomes blurred in many instances.

For the earth sciences, the NSF Earth Sciences Division is responsible for supporting basic and applied research. The research includes studies of the earth's evolution, the nature and distribution of its chemical and physical properties, and the mechanisms and processes that contribute to its formation. Results help to explain the chemical and physical relationships that produce landforms, mineral resources, and the environmental changes that affect human survival on planet earth.

The objective of earth sciences is to achieve greater understanding about the physical structure and chemical composition of the earth and the geologic processes that have led to its evolution. The focus is primarily on 
the constitution of the earth's lithosphere, which includes the upper mantle, crust, continents and plates. Emphasis is on the application of plate tectonics to the study of the origin and evolution of the continents. Research in geology, geophysics, geochemistry, petrology, and related fields contributes to an understanding of how the planet works; it also provides fundamental knowledge leading to advances in mineral and energy resources development, mitigation of geologic hazards, and better maintenance of the environment. 